OPEN ACCESS

Edited by:

Lia Fernandes,

University of Porto, Portugal

Reviewed by:

Rui Lopes,

University of Porto, Portugal Joao Antonio Pinto-de-Sousa,

University of Porto, Portugal

*Correspondence:

Ganna Androsova

Bioinformatics core, Luxembourg Centre for Systems Biomedicine (LCSB), University of Luxembourg, Avenue des Hauts Fourneaux 7 , Belval, 4362, Belvaux, Luxembourg ganna.androsova@uni.lu

Received: 20 January 2015 Accepted: 28 May 2015 Published: 09 June 2015

Citation: Androsova G, Krause R, Winterer G and Schneider R (2015) Biomarkers of postoperative delirium and cognitive dysfunction. Front. Aging Neurosci. 7:112. doi: 10.3389/fnagi.2015.00112

\section{Biomarkers of postoperative delirium and cognitive dysfunction}

\author{
Ganna Androsova ${ }^{1 *}$, Roland Krause ${ }^{1}$, Georg Winterer ${ }^{2}$ and Reinhard Schneider ${ }^{1}$ \\ ${ }^{1}$ Bioinformatics core, Luxembourg Centre for Systems Biomedicine (LCSB), University of Luxembourg, Belvaux, \\ Luxembourg, ${ }^{2}$ Experimental and Clinical Research Center (ECRC), Department of Anesthesiology and Operative Intensive \\ Care Medicine, Charité University Medicine Berlin, Berlin, Germany
}

Elderly surgical patients frequently experience postoperative delirium (POD) and the subsequent development of postoperative cognitive dysfunction (POCD). Clinical features include deterioration in cognition, disturbance in attention and reduced awareness of the environment and result in higher morbidity, mortality and greater utilization of social financial assistance. The aging Western societies can expect an increase in the incidence of POD and POCD. The underlying pathophysiological mechanisms have been studied on the molecular level albeit with unsatisfying small research efforts given their societal burden. Here, we review the known physiological and immunological changes and genetic risk factors, identify candidates for further studies and integrate the information into a draft network for exploration on a systems level. The pathogenesis of these postoperative cognitive impairments is multifactorial; application of integrated systems biology has the potential to reconstruct the underlying network of molecular mechanisms and help in the identification of prognostic and diagnostic biomarkers.

Keywords: postoperative delirium, postoperative cognitive dysfunction, biomarker, systems biology, POD, POCD

\section{Introduction}

More than $40 \%$ of surgical procedures in the US are performed on patients aged 65 and over Control Prevention Centers for Disease (2010). Elderly patients frequently experience postoperative cognitive impairment, characterized by progressive cognitive and sensory decline. An acute phase of cognitive impairment is postoperative delirium (POD; according to DSM-5: 293.0 "Delirium Due to Another Medical Condition"; Rudolph et al., 2008a). Deliria are further classified by duration and level of activity such as hyperactive, hypoactive or mixed. Patients with POD frequently develop a chronic phase of cognitive impairment, i.e., postoperative cognitive dysfunction (POCD; according to DSM-5: 294.10/11 "Major Neurocognitive Disorder Due to Another Medical Condition Without/With Behavioral Disturbance" or 331.83 "Mild Neurocognitive Disorder Due to Another Medical Condition"; Rudolph et al., 2008a). POCD is developed in $32 \%$ of patients with short delirium duration (1-2 days) and in $55 \%$ of patients with longer delirium (Rudolph et al., 2008a). The incidence of POD/POCD varies depending on the study and type of surgery; as illustrated on Figure 1, POD incidence ranges from 13.2\% to $41.7 \%$ and POCD incidence ranges from $8.9 \%$ to $46.1 \%$. The prevalence of POD and POCD is associated with higher mortality, increased incidence of postoperative complications, longer duration of hospital stay, greater utilization of social financial assistance and earlier retirement (Greene et al., 2009; Robinson et al., 2009; Steinmetz et al., 2009; Ansaloni et al., 2010; Liu et al., 2013). Patients older than 65 are predisposed to POD and POCD if they have hypoalbuminemia, 


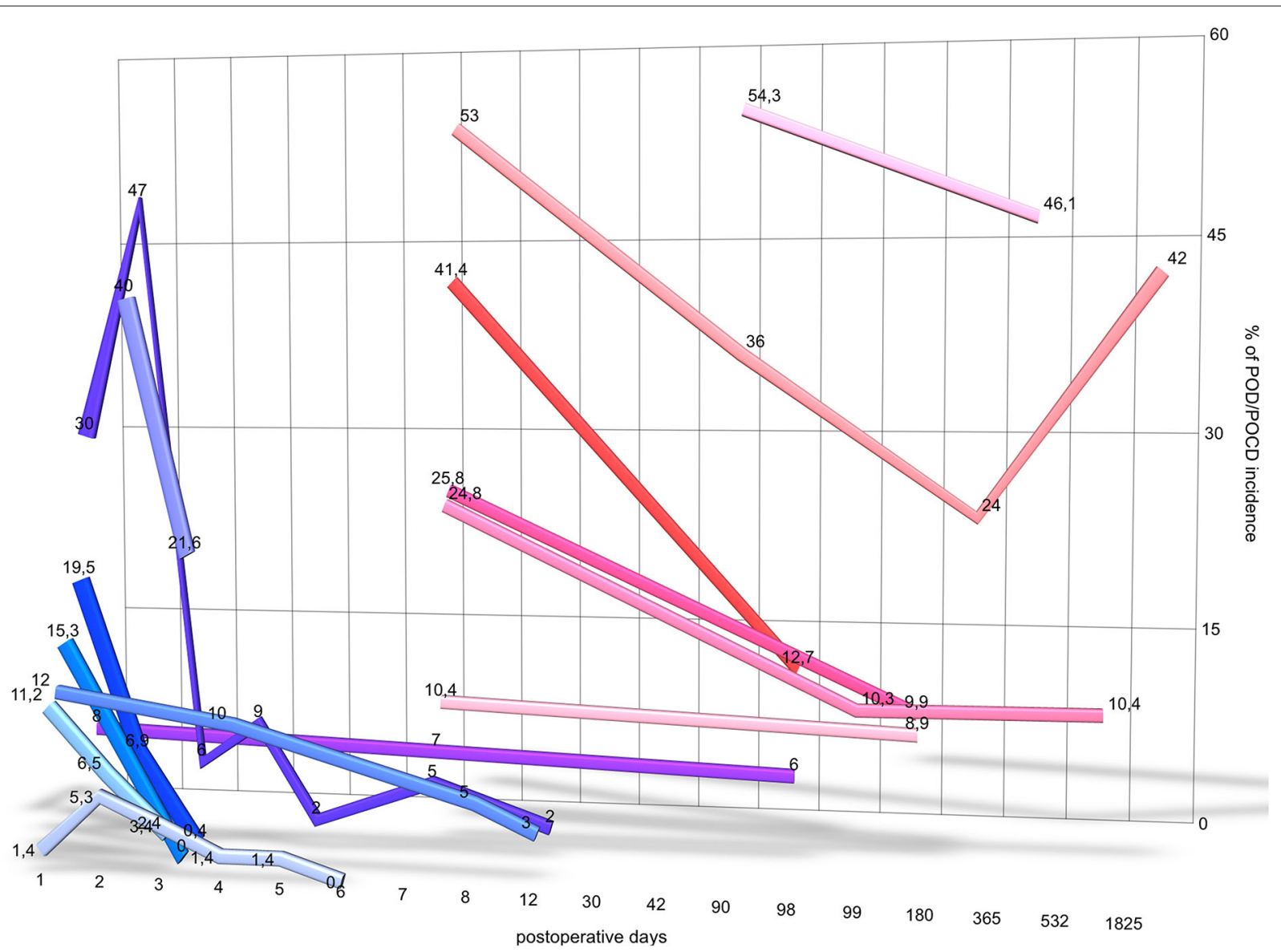

- POD after emergency and elective surgery (Ansaloni et al., 2010)

$\equiv$ POD after major NCS (Liu et al., 2013)

- POD at elderly medical unit (Adamis et al., 2009)

- POD after major NCS (Leung et al., 2007)

- POD after open heart surgery (Chang et al., 2008)

- POD after elective or urgent cardiac surgery (Schoen et al., 2011)

-POD after major abdominal, thoracic or vascular surgery (Robinson et al., 2009)

FIGURE 1 | Incidence and time-course of postoperative delirium (POD) and postoperative cognitive dysfunction (POCD) incidence. $Y$-axis denotes the percentage on POD/POCD incidence registered by the different studies. $X$-axis denotes the number postoperative days on
-POD and POCD after elective NCS (Rudolph et al., 2008a)

=POCD after major NCS (Monk et al., 2008)

—POCD after CABG (Newman et al., 2001)

- POCD after major abdominal, noncardiac thoracic, or orthopaedic surgery (Moller et al., 1998)

$\square \mathrm{POCD}$ after major abdominal, noncardiac thoracic, or orthopaedic surgery (Abildstrom et al., 2000)

—POCD after major or minor NCS (Abildstrom et al., 2004)

-POCD after elective vascular, thoracic, or major orthopedic surgery (McDonagh et al., 2010)

logarithmic scale. The graph does not include the data of POD/POCD incidence, if it was measured only once postoperatively, if measurement time was not precisely stated or the study includes less than 140 patients. CABG, coronary artery bypass grafting; NCS, noncardiac surgery. abnormal preoperative serum sodium, potassium, glucose or blood sugar levels as well as psychopathological symptoms, alcohol abuse or co-morbidities (Moller et al., 1998; Abildstrom et al., 2000; Newman et al., 2001; Chang et al., 2008; Monk et al., 2008; Deiner and Silverstein, 2009; Ansaloni et al., 2010; Kazmierski et al., 2014b). The cognitive status of elderly patients including depression, dementia or cognitive impairment is a significant risk factor for development of POD (Elie et al., 1998;
Leung et al., 2005; Minden et al., 2005; Inouye, 2006; McAvay et al., 2007; Greene et al., 2009; Kosar et al., 2014). For instance, dementia is a significant risk factor that increases delirium occurrence risk by fivefold (Elie et al., 1998); vice versa, delirium itself may lead to dementia and long-term cognitive deterioration (Jackson et al., 2004).

Postoperative delirium is defined in DSM-5 by several criteria including clouding of consciousness with reduced 
awareness of environment and difficulty in sustaining and/or shifting attention. In addition, POD is characterized by changes in cognition that affect memory, language and orientation in time/space (American Psychiatric Association, 2013). The impairment of memory, perceptual-motor abilities, language and attention are transit characteristics between POD and POCD. Memory impairment significantly affects cognitive decline and leads to impaired social and professional functioning in POCD patients. Memory deterioration lasting more than 1 month signifies the entry into the chronic phase of the cognitive impairment (American Psychiatric Association, 2013). POCD following delirium might increase the rate of cognitive deterioration in Alzheimer's disease (Gross et al., 2012). Specific characteristics of POCD include decline in speed of processing the information and disturbance in executive functioning but the patient typically remains oriented to person, time and space (Tsai et al., 2010). The decline in POCD is mostly recognized by comparison to the patient's pre-operative capabilities (Deiner and Silverstein, 2009). Delirium is usually measured by standardized clinical tests such as the Confusion Assessment Method (Inouye et al., 1990).

To improve diagnosis and treatment of POD/POCD, research aimed to identify prognostic and diagnostic biological markers. Biomarkers can determine severity and phase of the cognitive impairment, stratify patients who are likely to respond to specific treatment and monitor the efficiency of the treatment. Genetic markers (Papadopoulou et al., 2006), RNA (Sørensen and Ørntoft, 2010) and microRNA (Scherzer et al., 2007) levels, proteins (Wang et al., 2005), and post-translational changes such as glycosylation (Norton et al., 2008; Drake et al., 2010) and phosphorylation (Deguchi et al., 2002), have been demonstrated as prognostic biomarkers in a variety of diseases including disorders of the central nervous system (CNS) and these biochemical entities should be considered as possible markers for POD and POCD.

The most prominent hypothesis for the molecular mechanisms of POD and POCD is a central cholinergic deficiency caused by deregulation of cholinergic antiinflammatory pathways leading to increased inflammation (Inouye, 2006). Despite detection of decreased acetylcholine levels, several studies reported contradictory findings regarding levels of serum anticholinergic activity (SAA; see Section Biological Markers of Postoperative Delirium). Another suggestion is that delirium is caused by a combination of dopamine excess and acetylcholine deficiency (Trzepacz, 2000). Low tryptophan levels can be associated with delirium via decreased synthesis of brain serotonin or alteration of melatonin production, which has been challenged (see Section Biological Markers of Postoperative Delirium). The association between POD/POCD and pro-inflammatory cytokines such as tumor necrosis factor- $\alpha$, interleukin-1beta, interleukin-6 and interleukin-8, neuronal injury marker and C-reactive protein was shown by several studies and questioned by others (see Sections Biological Markers of Postoperative Delirium and Common Biomarkers of Postoperative Delirium and Cognitive Dysfunction for Details). Some POD/POCD patients have elevation in serum cortisol levels that may be explained by genetic variation of the glucocorticoid receptor gene (Perroud et al., 2011). The isoforms of apolipoprotein $\mathrm{E}$ can provoke cholinergic deficiency and acetylcholinesterase unblocking (Soininen et al., 1995), although some results are contradicting. The amyloid beta peptide associated with Alzheimer's disease was also observed in the serum of POCD patients. These and other findings are discussed in details in Sections Biological Markers of Postoperative Delirium, Common Biomarkers of Postoperative Delirium and Cognitive Dysfunction and Biological Markers of Postoperative Cognitive Dysfunction.

Here we review the known genetic risk factors and physiological and immunological changes that have been associated with POD and POCD. Deiner and Silverstein reviewed the postoperative delirium and cognitive dysfunction in 2009. More recent reviews discussed biomarkers and genetic variance for delirium alone (Khan et al., 2011; Stoicea et al., 2014). This article comprises a literature review on both POD and POCD biomarkers with a focus on recent findings. The current knowledge about the contributing biomarkers to postoperative delirium and cognitive dysfunction is summarized in Figure 2. POD and POCD have a wide range of contributing mechanisms and some biomarkers are overlapping. A more detailed description of the known and potentially novel biomarkers is provided below.

\section{Biological Markers of Postoperative Delirium}

The leading hypothesis suggests that delirium can be caused by a central cholinergic deficiency (Inouye, 2006) and is based on treatment with drugs which impair cholinergic function (Tune et al., 1981). The impact on muscarinic anticholinergic burden can be measured by SAA (Plaschke et al., 2007b). Increase of SAA levels is correlated with greater number of delirium symptoms, whereas SAA decrease is correlated with delirium resolution (Mach et al., 1995; Flacker et al., 1998; Mussi et al., 1999). Several studies questioned the association between SAA and delirium, considering that a temporal profile of SAA can be influenced by pre-existing cognitive impairment, infection or illness (Flacker and Lipsitz, 1999; Plaschke et al., 2007a; van Munster et al., 2012). The impact of drugs on the cholinergic system was addressed in detail by Fox et al. (2014) and Praticò et al. (2005).

Acetylcholine plays an important role in memory, associative learning and selective attention (Hasselmo, 1995; Everitt and Robbins, 1997). Impairment of its receptors, such as nicotinic and muscarinic acetylcholine receptors, might lead to cholinergic deficiency and delirium development (Hshieh et al., 2008). Postsynaptic M1 muscarinic receptors are predominantly expressed in hippocampus, cerebral cortex and striatum (Hersch et al., 1994; Levey, 1996) and play a role in cognitive functioning, memory and learning (Anagnostaras et al., 2003; Volpicelli and Levey, 2004; Fisher, 2008). Inhibition of the M1 muscarinic receptor was hypothesized to cause POD and POCD (Praticò et al., 2005). Inhibition of postsynaptic nicotinic receptors by 


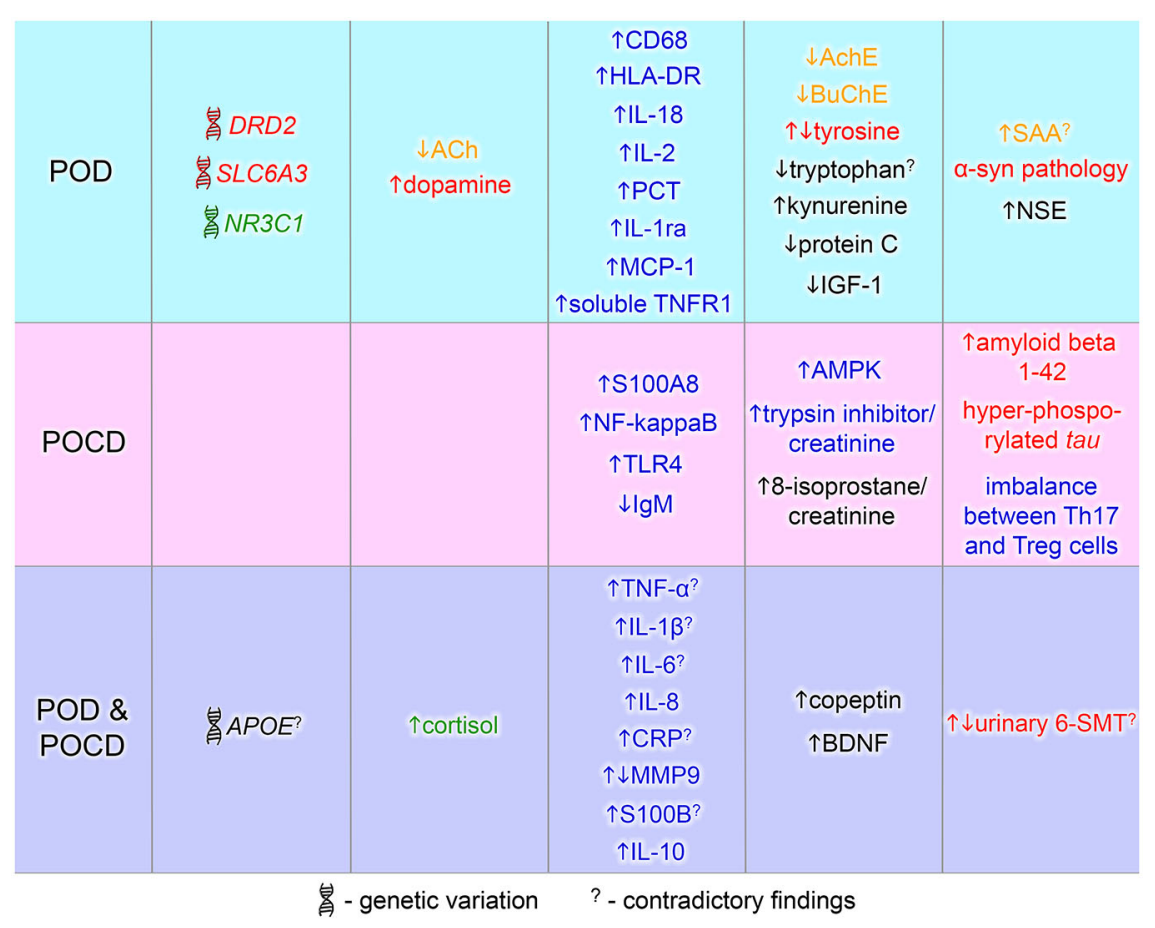

FIGURE 2 | Biomarkers of postoperative delirium (POD) and postoperative cognitive dysfunction (POCD). Biomarkers identified in POD or POCD patients are in blue and pink area respectively. The common POD/POCD biomarkers are presented in the violet area. Font color denotes a marker type: red-dopamine-related marker, green-glucocorticoid-related marker, yellow-cholinergic marker, blue-inflammation-related marker, black-others. 6-SMT,

6-sulfatoxymelatonin; ACh, acetylcholine; AchE, acetylcholinesterase; AMPK, $5^{\prime}$ adenosine monophosphate-activated protein kinase; $A P O E$, apolipoprotein E; BDNF, brain-derived neurotrophic factor; BuChE, butyrylcholinesterase; CD68, cluster of differentiation 68; CRP, C-reactive protein; DRD2, dopamine receptor D2; HLA-DR, human leukocyte antigen-DR; IGF-1, insulin growth factor-1; IgM, immunoglobulin M; IL, interleukin; MCP-1, monocyte chemotactic protein 1; MMP9, matrix metalloproteinase-9; NF-kappaB, nuclear factor kappa B; NR3C1, nuclear receptor family 3 , group $\mathrm{C}$, member 1 ; NSE, neuron specific enolase; PCT, procalcitonin; S100A8, S100 calcium binding protein A8 (myeloid-related protein-8, calgranulin A); S100B, S100 calcium binding protein B; SAA, serum anticholinergic activity; SLC6A3, solute carrier family 6 , member 3 ; Th17, T helper 17 cells; TLR4, toll-like receptor 4; TNF- $\alpha$, tumor necrosis factor- $\alpha$; TNFR1, tumor necrosis factor receptor-1; Treg, regulatory $T$ cells; $\alpha$-syn, alpha-synuclein. isoflurane and nitrous oxide results in learning and memory impairment after surgery (Culley et al., 2003; Kong et al., 2015). Vice versa, agonists of the nicotinic receptors can improve cognitive function (Wagner et al., 2013): activation of the nicotinic acetylcholine receptor alpha 7 prevents the cognitive decline after surgery by inhibition of NF-kappaB (nuclear factor kappa B) activation and suppression of macrophage migration into the hippocampus (Terrando et al., 2011). This phenomenon shows the bidirectional communication between the nervous and the immune system (Ader et al., 1995). Therefore, acetylcholine and its receptors are likely contributors to the onset of POD and POCD.

The cholinergic anti-inflammatory pathway, mediated by acetylcholine, is associated with neurocognitive decline (Ramlawi et al., 2006). It suppresses NF-kappaB activation and inhibits the release of inflammatory cytokines (e.g., tumor necrosis factor, interleukin (IL)-1 $\beta$, IL-6, and IL-18) but not IL-10, an anti-inflammatory cytokine (Borovikova et al., 2000; van Gool et al., 2010). Septic and aseptic inflammation can trigger acute cognitive deficits in patients with cholinergic system depletion (Field et al., 2012). Acetylcholinesterase and butyrylcholinesterase inactivate acetylcholine through hydrolysis, possibly enhancing inflammation. Decreased cholinesterase activity in delirious patients was correlated with elevated levels of C-reactive protein and IL-6 (Cerejeira et al., 2012). C-reactive protein (CRP) is a marker of nonspecific acute-phase response in inflammation, infection and tissue damage (Pepys and Hirschfield, 2003), correlated with cognitive decline (Tilvis et al., 2004). The association between high CRP levels and delirium was shown by several studies (Beloosesky et al., 2004; Macdonald et al., 2007; Burkhart et al., 2010; Pol et al., 2014; Ritchie et al., 2014; Zhang et al., 2014b), and questioned by others (Lemstra et al., 2008; Girard et al., 2012).

An inflammatory response to postoperative stress may contribute to delirium via disruption of the blood-brain barrier (Rudolph et al., 2008b). The increased risk is correlated with elevated monocyte chemotactic protein 1, procalcitonin, human leukocyte antigen-DR, CD68, IL-1 $\beta$, IL-6, IL-8, IL-18 and antiinflammatory IL-1 receptor antagonist (van Munster et al., 2008, 
2011a; van den Boogaard et al., 2011; Cape et al., 2014). Elevated levels of the pro-inflammatory cytokines IL-2 and tumor necrosis factor- $\alpha$ (TNF- $\alpha)$ were detected in the POD patients who had undergone coronary artery bypass graft surgery (Kazmierski et al., 2014a,b). Inhibition of inflammatory IL-12/IL-23-mediated pathways may reduce Alzheimer's disease pathology and reverse cognitive deficits in aged mice (Vom Berg et al., 2012). van Munster et al. (2011b) observed high levels of IL-8 and cortisol before a delirium onset and high levels of IL-6 and S100 calcium-binding protein B (S100B) in the course of delirium but functional genetic variations in interleukin-6 gene (IL6), interleukin-6 receptor gene (IL6R) and interleukin-8 gene (IL8) were not associated with delirium (van Munster et al., 2011b). Likewise, the association between delirium and higher IL-1, IL- 6 and TNF- $\alpha$ plasma levels was not confirmed (Adamis et al., 2007, 2009). The lower plasma concentrations of the coagulation marker protein $\mathrm{C}$ together with elevated plasma concentrations of soluble tumor necrosis factor receptor-1 were associated with increased risk for delirium (Girard et al., 2012).

S100B is an indicator of the direct neuronal injury, e.g., by cerebrovascular accidents and traumatic brain injury (Berger et al., 2005). Several studies consistently demonstrated highly elevated levels of S100B in patients with delirium (Pfister et al., 2008; van Munster et al., 2009b, 2010a,c; van den Boogaard et al., 2011). Grandi et al. (2011) found no difference in levels of S100B in delirious and control patients. The same study indicated that neuron-specific enolase and brain-derived neurotrophic factor (BDNF) could be potential biomarkers for delirium in intensive care unit patients (Grandi et al., 2011). BDNF plays role in synaptic plasticity, neuronal survival, differentiation and growth (Acheson et al., 1995; Huang and Reichardt, 2001). Similarly to BDNF, insulin growth factor-1 (IGF-1) promotes neuronal proliferation, development, survival and enhanced synaptic transmission in CNS (Frost et al., 2003; Shcheglovitov et al., 2013; Huat et al., 2014). Tumor necrosis factor- $\alpha$ (TNF- $\alpha)$ can be involved in neurodegeneration through inhibition of IGF-1 (Frost et al., 2003; Bassil et al., 2014). Low baseline levels of IGF-1 were associated with an increased risk of delirium incidence (Wilson et al., 2005; Adamis et al., 2007, 2009). Due to the neuroprotective function, low levels of IGF-1 may have a significant effect on delirium severity (Adamis et al., 2009). Understanding the complex connection between the cholinergic system and increased pro-inflammatory response as well as neurodegeneration is likely to shed light on the molecular and cellular causes of delirium.

Another popular hypothesis suggests that delirium can be caused by dopamine excess and acetylcholine deficiency relative and/or absolute to each other (Trzepacz, 2000). Cytokines can disrupt the neurotransmitter system balance, leading to reduced acetylcholine release (Willard et al., 1999) and increased dopamine and norepinephrine release (Stefano et al., 1994). Delirium, related to anticholinergic mechanisms, was successfully treated with the dopamine receptor antagonists (Alagiakrishnan and Wiens, 2004). One of such receptors is dopamine receptor D2 (DRD2); its dysfunction leads to hallucinations, impairment of motor and frontal lobe functions (Volkow et al., 1998; Makoff et al., 2000). The gene encoding for $\mathrm{D}_{2}$ subtype of dopamine receptor (DRD2) was associated with schizophrenia and movement disorders (Kukreti et al., 2006; Koning et al., 2012). Seven single nucleotide polymorphisms (SNPs) in the SLC6A3 (solute carrier family 6, member 3) gene and three genetic polymorphisms in the DRD2 gene are associated with delirium (van Munster et al., 2010d). The SLC6A3 gene is coding for the dopamine transporter, hence variation of this gene can lead to a lower concentration of cerebral basal dopamine, diminishing the risk of delirium (van Munster et al., 2010b). One of the detected genetic polymorphisms in SLC6A3 was associated with pediatric bipolar disorder (Mick et al., 2008); although no connection was found between bipolar disorder in adults and postoperative delirium.

Apolipoprotein E (ApoE) regulates the cholesterol metabolism, participates in repairing and maintaining of neuronal membranes and myelin during development and after injury (Ignatius et al., 1986). It is responsible for cholinergic neuron destruction by increased synthesis and defective clearance of amyloid beta (Kowall et al., 1991). Different isoforms of $A P O E$ gene can provoke cholinergic deficiency and acetylcholinesterase unblocking (Soininen et al., 1995). The carriers of $A P O E \& 4$ allele have greater risk of delirium development (Adamis et al., 2007; Leung et al., 2007; van Munster et al., 2009a) and are more predisposed to cellular damage within the brain (Olivecrona and Koskinen, 2012). The APOE \&4 allele was found to be correlated with longer duration of delirium in mechanically ventilated critically ill patients (Ely et al., 2007). There might be a connection between neurodegeneration due to pro-inflammatory response and enhanced $A P O E$ activity that causes cholinergic deficiency in POD patients. Even so, some studies question the association of $A P O E \varepsilon 4$ with delirium (Adamis et al., 2009; Bryson et al., 2011; Abelha et al., 2012).

Elevated serum cortisol levels were correlated with POD risk and degree, being dependent on hypothalamic-pituitaryadrenal axis hyperactivity at preexisting cognitive and functional impairment (van Munster et al., 2010a; Bisschop et al., 2011; Cerejeira et al., 2013; Colkesen et al., 2013; Kazmierski et al., 2013). A possible epigenetic explanation of cortisol sensitivity is the methylation of the glucocorticoid receptor gene NR3C1 (nuclear receptor family 3, group C, member 1; Perroud et al., 2011). The increased diurnal cortisol and higher sensitivity to glucocorticoids were associated with homozygous NR3C1 haplotype 4 (Manenschijn et al., 2011). The carriers of this haplotype had a 92\% decreased risk of developing POD independently of age, cognitive and functional state (Manenschijn et al., 2011). This study concluded that development of delirium and its pathogenesis is correlated with glucocorticoid signaling. High levels of glucocorticoids affect working memory and thereby explain the cognitive deficits and inattention (Lupien et al., 1999). Mild cognitive impairment was further associated with increased cortisol levels and POD risk (Kazmierski et al., 2014b). 
The neurometabolic pathway facilitates communication between brain and metabolic organs and consequently influences various neurodegenerative disorders, normal and pathophysiological aging (Siddiqui et al., 2012). Alteration in the neurometabolic status of the hippocampus can potentially impair growth and survival of neuronal cells, which is a common neuropathology of Alzheimer's disease (Wenk, 2003; Cong et al., 2013). Metabolic syndrome (e.g., hyperglycemia, diabetes) together with inflammation can contribute to cognitive decline (Yaffe et al., 2004). Prevention of metabolic syndrome by preoperative conventional glucose control might reduce the incidence of POD/POCD (Yaffe et al., 2004; Finfer et al., 2009).

The changes of amino acid concentrations in serum and urine have been associated with POD pathogenesis. An increased risk of delirium development was associated with decreased plasma tryptophan and the ratio of tryptophan as well as the increased or decreased ratio of tyrosine to large neutral amino acids (van der Mast et al., 2000; Robinson et al., 2008; Pandharipande et al., 2009). It was hypothesized that high levels of tyrosine lead to dopamine and norepinephrine excess that are involved in delirium pathogenesis (Pandharipande et al., 2009).

The low tryptophan levels might be associated with delirium via decreased synthesis of brain serotonin (van der Mast et al., 2000; Robinson et al., 2008; Pandharipande et al., 2009). de Jonghe et al. (2012) questioned the association between lower levels of tryptophan and delirium. Following the inflammatory response, tryptophan catabolisation via the kynurenine pathway is increased (Adams Wilson et al., 2012). Elevated plasma kynurenine and kynurenine/tryptophan ratio were correlated with fewer days without acute brain dysfunction in form of delirium or coma (Adams Wilson et al., 2012). Another suggested connection of tryptophan with delirium is alteration of melatonin production via serotonin synthesis (Pandharipande et al., 2009). Melatonin participates in regulation of circadian rhythms and quality and duration of sleep (Brzezinski, 1997). POD patients frequently have disrupted sleep-wake cycle, decreased delta melatonin concentrations (Yoshitaka et al., 2013) and abnormal circadian postoperative patterns of melatonin secretion (Shigeta et al., 2001).

Sunwoo et al. (2013) observed a higher frequency of normal and phosphorylated $\alpha$-synuclein-positive pathologies in 16 delirious patients that underwent gastrostomy for stomach cancer. Sunwoo and colleagues concluded that POD clinical characteristics are analogous to the core features of $\alpha$ - as dementia with Lewy bodies, Parkinson disease dementia; patients experience altered sleep-wake cycles, visual hallucinations, disorganized thinking and attention impairment (Sunwoo et al., 2013). $\alpha$-synuclein may be involved in the neurotransmitter release controlling through the SNARE complex (Kang et al., 1987; Tanzi et al., 1987). The delirious state is strongly influenced by the balance between cholinergic and dopaminergic systems, pro-inflammatory signaling, apolipoprotein E isoform, glucocorticoid signaling and the neurometabolic state. Many additional contributors at genetic, proteomic, metabolic and immune levels are to be expected.

\section{Common Biomarkers of Postoperative Delirium and Cognitive Dysfunction}

Postoperative delirium correlates with early postoperative cognitive dysfunction (at 7 days; Rudolph et al., 2008a; Hudetz et al., 2009) and delirious patients have 14 times greater chance of POCD development (Hudetz et al., 2009). In this chapter, we will discuss the common biomarkers found in both cognitive impairments, which are summarized in Figure 2.

Among the above-discussed genetic markers, the $A P O E \& 4$ allele was associated with greater risk to develop postoperative delirium (Adamis et al., 2007; Leung et al., 2007; van Munster et al., 2009a) and cognitive dysfunction at 7 days postoperatively (Cao et al., 2014). The association with POCD was however not detected by other studies of APOE $\varepsilon 4$ variation at 1 week, 1-3 months and 1 year postoperatively (Abildstrom et al., 2004; Rentowl and Hanning, 2004; McDonagh et al., 2010; Bryson et al., 2011; Cao et al., 2014).

The elevated cortisol levels were detected in both POD (van den Boogaard et al., 2011; Cerejeira et al., 2013) and POCD patients (Zhang et al., 2014a). The magnitude of cortisol elevation correlated with levels of anti-inflammatory cytokine IL-10 and pro-inflammatory cytokine IL-6. Similarly to POD, POCD is associated with elevation of other pro-inflammatory markers including IL-1 $\beta$, IL- 8 and TNF- $\alpha$ (Rothenburger et al., 2001; Hudetz et al., 2011; Li et al., 2012; Bi et al., 2014). TNF- $\alpha$ stimulates IL-1 $\beta$ production in the brain and causes postoperative cognitive decline via peripheral cytokine cascade (Terrando et al., 2010). Reducing IL-1 release by peripheral TNF- $\alpha$ blockade might prevent POD, POCD and neuroinflammation (Terrando et al., 2010). Nonspecific acutephase response in inflammation is present during POD and POCD. POCD patients have elevated levels of CRP following coronary artery bypass grafting (Hudetz et al., 2011), liver transplantation (Li et al., 2013b) and lumbar discectomy (Zhang et al., 2014a). Contradictory to previous findings, plasma levels of inflammatory marker matrix metalloproteinase- 9 were decreased in POD patients and elevated in POCD patients (Girard et al., 2012; Zhang et al., 2014a).

Elevated levels of S100B were associated with POD (Pfister et al., 2008; van Munster et al., 2009b, 2010a,c; van den Boogaard et al., 2011). Likewise, POCD patients have increased serum levels of S100B, which is an indicator of neuronal injury (Rasmussen et al., 2000; Li et al., 2012; Lili et al., 2013). S100Binduced neuroinflammation mediates the RAGE (receptor for advanced glycation end product) signaling in microglia (Bianchi et al., 2007). The RAGE signaling pathway may up-regulate proinflammatory cytokines via NF-kappaB signaling, indicating its possible role in surgery-induced cognitive decline pathogenesis (Li et al., 2013a). Yet McDonagh et al. (2010) did not find an association between POCD and S100B or CRP.

BDNF showed correlation with POD occurrence in patients (Grandi et al., 2011) and POCD occurrence in aged mice (Tian et al., 2015). It was associated with other neuropsychiatric disorders such as schizophrenia, depression, bipolar disorder and has been suggested as early marker of brain injury (Chiaretti et al., 2003; Muglia et al., 2003; Teixeira et al., 2010). 
Copeptin is correlated with severity of the illness and is presumed to be a prognostic measure of outcome prediction in acute illness (Katan and Christ-Crain, 2010). Postoperative plasma copeptin level can be an independent predictor of POD and POCD after coronary artery bypass graft surgery (Dixson et al., 2014). This study observed higher levels of postoperative copeptin in POD and POCD patients compared to controls.

A significant fluctuation of urinary 6-sulfatoxymelatonin (6-SMT), a major metabolite of melatonin, was detected in POCD patients compared to controls (Wu et al., 2014). Clinical subtypes of POD are differently related to the urinary levels of 6-sulfatoxymelatonin: hypoactive patients have higher 6-SMT, whenever hyperactive patients have lower 6-SMT (Balan et al., 2003). However, the association between melatonin and delirium has been challenged by independent studies after failure to confirm these findings (de Jonghe et al., 2014).

As mentioned above, postoperative delirium and cognitive dysfunction may have common contributing factors and biomarkers such as apolipoprotein E isoforms, cortisol signaling, pro-inflammatory cytokines, neurodegenerative marker S100B, copeptin and 6-sulfatoxymelatonin levels.

\section{Biological Markers of Postoperative Cognitive Dysfunction}

Patients with postoperative cognitive dysfunction display biomarkers distinct from delirious patients, which might be related not only to pathology but also postoperative time. The majority of the detected POCD biomarkers are related to inflammation. A recent study reported a positive association between the pro-inflammatory protein S100A8 and POCD development (Lu et al., 2015) and imbalance between T helper 17 cells, a pro-inflammatory subset of $\mathrm{CD} 4^{+} \mathrm{T}$ cells, and regulatory $\mathrm{T}$ cells, an anti-inflammatory subset of $\mathrm{CD} 4^{+} \mathrm{T}$ cells, was observed in POCD patients (Tian et al., 2015).

Postoperative cognitive dysfunction can be predicted by lower preoperative endotoxin immunity following cardiac surgery (Mathew et al., 2003). Lower preoperative levels of immunoglobulin $\mathrm{M}$ (anti-endotoxin core antibody) are associated with the greater incidence and severity of POCD (Mathew et al., 2003). A similar study by Rothenburger et al. (2001) suggested an association between lower levels of immunoglobulin $\mathrm{M}$ and elevated levels of endotoxin together with IL-8 (Rothenburger et al., 2001).

$5^{\prime}$ adenosine monophosphate-activated protein kinase (AMPK) protects CNS by inhibition of inflammatory responses through various mechanisms, including NF-kappaB pathway (Sag et al., 2008; Salminen et al., 2011). This pathways includes NF-kappaB activation by chemokines, cytokines or adhesion molecules and activation of inflammatory cytokines IL-1 and TNF- $\alpha$ (Renard et al., 1997; Chandel et al., 2000). A significant elevation of NF-kappaB, IL-1 $\beta$ and AMPK was shown to result in Toll-like receptor 4 signaling on microglia in the hypothalamus of a POCD rat model (Wang et al., 2013; Bi et al., 2014). Interleukin-1 $\beta$ and NF-kappaB levels gradually decreased over postoperative days (Wang et al., 2013; Bi et al., 2014).
Interleukin- $1 \beta$ can be a viable target to interrupt the POCD pathogenesis, as IL-1 $\beta$-mediated inflammation was triggered by peripheral surgery-induced innate immune response (Cibelli et al., 2010). Another study demonstrated experimentally that inhibition of IL-1 receptors prevents development of POCD and neuroinflammation (Barrientos et al., 2012).

Le et al. (2014) suggested that hippocampus impairment leads to POCD development after they observed a significant reduction of neuronal dendritic spines and neuroinflammation signified by activated microglia, elevation of TNF- $\alpha$ and interleukin- $1 \beta$ in the hippocampi of aged rats. Amyloid beta 1-42 oligomers can impair cognitive and metabolic processes in the hippocampus (Pearson-Leary and McNay, 2012). The elevated levels of amyloid beta 1-42 were associated with a cognitive impairment caused by its interference with insulin signaling in the hippocampus (Pearson-Leary and McNay, 2012). The amyloid hypothesis suggests that amyloid beta peptide is deposited in the brain of Alzheimer's dementia patients and can form the senile plaques that perturb various signaling mechanisms (Cras et al., 1991). Old mice that developed short-term POCD upon abdominal surgery had Alzheimer's dementia-like changes: gliosis in brain, enhanced transcriptional and translational activity of the $\beta$ amyloid precursor protein, enhanced production of amyloid beta peptide, and hyper-phosphorylation of tau in the hippocampus (Wan et al., 2010). POCD patients after liver transplantation had significantly elevated levels of serum amyloid beta peptide, suggesting similar mechanisms as in Alzheimer's disease (Li et al., 2013b).

Urinary biomarkers could be promising diagnostic and prognostic indicators of postoperative cognitive dysfunction. A high ratio of trypsin inhibitor/creatinine was suggested to be an independent risk factor of POCD in lumbar discectomy patients (Zhang et al., 2014a). Urinary excretion levels of 8isoprostane/creatinine were elevated as well in POCD patients at 7 days postoperatively compared to control patients (Cheng et al., 2013).

The major POCD biomarkers include inflammation-related molecules, imbalance between pro- and anti-inflammatory signaling and metabolic levels in urine.

\section{Potential Biomarkers of Postoperative Delirium and Cognitive Dysfunction}

At present, there is no standard biomarker for diagnosis and prognosis of postoperative cognitive impairments. Some findings on biomarker association with POD/POCD are contradictory. Thus, generation of genomic, proteomic and metabolomics data as well as implementation of imaging techniques such as MRI are required. In this section, we review the potential biomarkers possibly involved in occurrence and/or progression of postoperative delirium and cognitive dysfunction.

S100A8 (myeloid-related protein-8, calgranulin A), S100A9 (myeloid-related protein-14, calgranulin B), S100A12 (ENRAGE, calgranulin C) are reliable markers of inflammation (Foell et al., 2004) and potential markers of plaque instability (Abbas et al., 2012). Inhibition of S100A9 significantly improved learning and memory, and reduced neuropathology of 
Alzheimer's disease (Chang et al., 2012). Thus, it is promising to investigate potential connection between the calgranulins and POD/POCD.

As mentioned above, inflammation is associated with both POD and POCD. The pro-inflammatory cytokine IL-18 was not studied yet in the context of POD/POCD. Alzheimer's patients have increased levels of IL-18 in different regions of the brain (Ojala et al., 2009). Being co-localized with tau-protein and amyloid beta plaques, IL-18 mediates the hyperphosphorylation of tau (Ojala et al., 2009; Sutinen et al., 2012). IL-18 can influence the integrity of neurons and increase neuroinflammation in the brain (Bossù et al., 2010; Sutinen et al., 2012), thus contributing to cognitive decline in Alzheimer's disease (Bossù et al., 2008). IL-18 receptor complex (IL-18R $\alpha / \beta$ ) expression is perturbed in preclinical state of mild cognitive impairment and Alzheimer's disease (Salani et al., 2013). Specifically, IL-18R $\alpha$ might play role in autoimmune brain damage (e.g., encephalomyelitis) via production of IL-17-producing T helper cells (Gutcher et al., 2006). A splice variant of IL-18R $\beta$ encodes a putative truncated soluble protein that might be a regulator of IL-18 functioning (Andre et al., 2003).

SIGIRR (also called TIR8) is a potential inhibitor of proinflammatory IL-18, IL-1 and Toll-like receptor signaling (Thomassen et al., 1999; Wald et al., 2003; Mantovani et al., 2004). The anti-inflammatory effect of SIGIRR might be extended to the brain, as it inhibits inflammation in cooperation with IL-1F5 (a potential anti-inflammatory cytokine; Costelloe et al., 2008). TIGIRR receptor might be an accessory chain for mature IL-37a (Boraschi et al., 2011). IL-37a isoform is exclusively located in the brain and might be a potential antiinflammatory cytokine (Boraschi et al., 2011). Another isoforms of IL-37 can bind to IL- $18 \mathrm{R} \alpha$ and IL-18-binding protein, enhancing IL-18 inhibition (Boraschi et al., 2011).

IL1RAPL (IL-1 receptor accessory protein-like) gene was identified as a X-linked mental retardation locus (Carrié et al., 1999). IL1RAPL gene encodes a protein homologous to the IL$1 /$ Toll receptor family. Patients with cognitive impairment had a nonsense mutation and deletions in IL1RAPL gene (Carrié et al., 1999). IL1RAPL gene might have a potential role in memory and learning functioning due to its over-expression in brain structures responsible for memory development such as hippocampus, dentate gyrus and entorhinal cortex (Carrié et al., 1999).

Several studies have reported a possible disruption of the blood-brain barrier integrity during POD (Pfister et al., 2008; Rudolph et al., 2008b). Blood-brain barrier disruption is associated with cognitive, behavioral and mood disturbances (Shalev et al., 2009). Zonulin is a protein that modulates the intercellular tight junction integrity and increases bloodbrain barrier permeability (Fasano et al., 2000). Zonulin is involved in movement of macromolecules, fluid and leukocytes between intestinal lumen and bloodstream ( $\mathrm{Lu}$ et al., 2000; Fasano, 2011). Since zonulin can increase intestinal and bovine brain microvessel endothelial cells permeability, the elevated circulating levels of zonulin can indicate blood-brain barrier pathologies (Karyekar et al., 2003; Fasano, 2011). Zonulin has been already associated with several diseases: celiac disease
(Fasano et al., 2000; Fasano, 2011), schizophrenia (Wan et al., 2007), Devic's disease (Bai et al., 2009), multiple sclerosis (Takeoka et al., 1983) and Guillain-Barré syndrome (Jin et al., 2007; Yang et al., 2008).

Cholinergic-nicotinic genes can be implicated in POD/POCD pathology. Genetic variation within exon 5 of the $\alpha 4$ subunit of nicotinic acetylcholine receptor (CHRNA4) gene can modulate the attention network function (Winterer et al., 2007) and was implicated in nicotine dependence (Feng et al., 2004; Li et al., 2005). Several rare CHRNA4 SNPs were negatively associated with nicotine dependence indicating its protective effect (Wessel et al., 2010; Xie et al., 2011). Nicotine can improve attention, memory and efficiently treat cognitive impairments (Rezvani and Levin, 2001). Patients with genetic variation of CHRNA4 might abuse nicotine as self-medication of attention deficits in autosomal dominant nocturnal frontal lobe epilepsy (Hirose et al., 1999; Cho et al., 2003), schizophrenia (Winterer et al., 2007; Winterer, 2010) and attention deficit/hyperactivity disorder (Lambert and Hartsough, 1998). In addition, variants on the CHRNA5-CHRNA3CHRNA4 gene cluster, implicated in nicotine dependence, are associated with cognitive performance (Winterer et al., 2010).

\section{System Biology Approaches for Biomarker Discovery}

To identify, prevent or treat postoperative delirium and cognitive dysfunction we need to connect the incidental findings into an encompassing model and relate the pathomechanisms underlying POD/POCD with clinical outcomes. The biomarkers discussed so far are conceptually linked by the known molecular interactions and pathways and illustrated in Figure 3. Many findings are contradictory between cohorts and studies, which further complicates the investigation of underlying mechanisms. The toolbox of integrated systems biology can help to model the complex dependencies and conceptualize the unknown pathomechanisms contributing to POD/POCD origin and progression. Due to the sparse knowledge on cognitive impairments, we are limited in the choice of methodologies. Predictions of novel targets for study cannot utilize the simulations as appropriately large training and test data needs yet to be collected.

Knowledge maps formed by an integration of large-scale experimental data and text-mining results enable specialists to collaborate on highly detailed information. The dissection of the knowledge map into functionally/pathway enriched modules can reduce the overall complexity and indicate the sub-network(s) deregulated in POD/POCD. Networks built on the list of the seed genes/proteins reviewed in this article may indicate enriched pathways that are related directly or indirectly to POD/POCD. We can proceed with prediction of the upstream regulators, hubs and bottlenecks of the given pathways and sub-networks. Such regulators are potentially interesting as targets since they could modulate the network state and dampen imbalance and deregulation. Network approach enables us to study dynamical changes of the system such as 


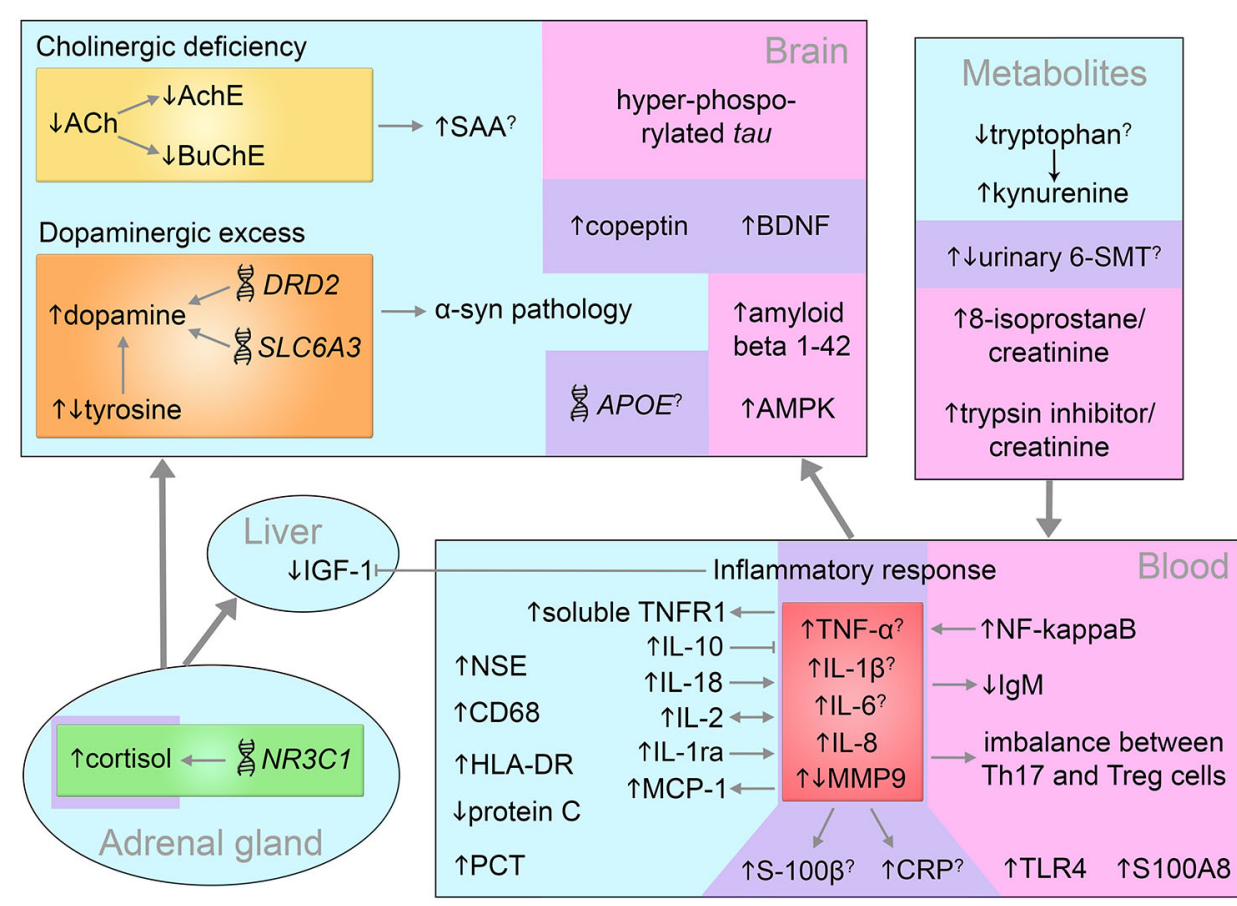

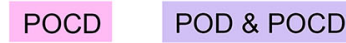

FIGURE 3 | Systems-level interaction of POD and POCD biomarkers Biomarkers identified in POD and POCD patients are in blue and pink area respectively. The common POD/POCD biomarkers are presented in the violet area. 6-SMT, 6-sulfatoxymelatonin; ACh, acetylcholine; AchE, acetylcholinesterase; AMPK, 5' adenosine monophosphate-activated protein kinase; $A P O E$, apolipoprotein E; BDNF, brain-derived neurotrophic factor; BuChE, butyrylcholinesterase; CD68, cluster of differentiation 68; CRP, C-reactive protein; DRD2, dopamine receptor D2; HLA-DR, human leukocyte antigen-DR; IGF-1, insulin growth factor-1; IgM, immunoglobulin

\section{㫷 - genetic variation ? - contradictory findings}

responsiveness, adaptation and stability. For example, network analysis of the metabolic positron emission tomography scans from Parkinson's disease patients identified two distinct diseaserelated patterns (Eckert et al., 2007). One of the patterns is related to motor manifestations of Parkinson's disease, the other pattern is correlated with the patients' performance on memory and executive functioning tests. In case of POD/POCD, networks can initially be based on the literature mining results where large-scale human experimental data is not accessible. Networks based on experimental data and supported by literature evidence may give stronger results and reflect the network dynamics.

Systems biology methods, applied to Parkinson's disease, made a significant contribution for integration of known pathomechanisms. Parkinson's disease is a multi-factorial condition with complex interplay between genetic and environmental factors (Calne et al., 1986). A recently published Parkinson's disease map is able to capture the known contributing mechanisms, integrate the underlying pathways and visualize large experimental data on top of the
$\mathrm{M}$; IL, interleukin; MCP-1, monocyte chemotactic protein 1; MMP9, matrix metalloproteinase-9; NF-kappaB, nuclear factor kappa B; NR3C1, nuclear receptor family 3 , group $\mathrm{C}$, member 1 ; NSE, neuron specific enolase; PCT, procalcitonin; S100A8, S100 calcium binding protein A8 (myeloid-related protein-8, calgranulin A); S100B, S100 calcium binding protein B; SAA, serum anticholinergic activity; SLC6A3, solute carrier family 6, member 3; Th17, T helper 17 cells; TLR4, toll-like receptor 4; TNF- $\alpha$, tumor necrosis factor- $\alpha$; TNFR1, tumor necrosis factor receptor-1; Treg, regulatory $\mathrm{T}$ cells; $\alpha$-syn, alpha-synuclein. solid, literature derived and reviewed network (Fujita et al., 2014). The principle of the Parkinson's disease map could be well applied to investigate other complex diseases including POD and POCD.

Magnetic resonance imaging revealed the vulnerable regions in brain of POD patients (Root et al., 2013) as well as white-matter hyperintensities (Hatano et al., 2013) and brain atrophy (Gunther et al., 2012). Integration of imaging results with information at different levels (i.e., DNA, RNA, proteins, etc.) gives a rise to mathematical/computational modeling of POD and POCD states. Iterative prediction and cross-validation steps improve such models and system behavior and response to perturbations can be predicted. For instance, neuroimaging integration with genetic and demographic information by a Support Vector Machine algorithm successfully differentiated Alzheimer disease and mild cognitive impairment from controls (Kohannim et al., 2010). The integrated systems biology approaches in the context of POD/POCD lead a step forward to personalized medicine and effective clinical trials. 


\section{Conclusion}

Postoperative delirium and cognitive dysfunction has been elucidated on the molecular basis and many biomarkers have been identified. Hypotheses to explain the major features of the disease onset and pathology were formulated but at this point, we understand little how much the markers and mechanisms explain the pathology. In particular, we know little about possible molecular influences on $\mathrm{POD} / \mathrm{POCD}$ sub-types such as slow and fast progression or hypo- and hyperactive delirium. Common molecular mechanisms with other syndromes, in particular schizophrenia, promise further insights but have not been investigated on a sufficient scale. As neuropsychiatric syndromes present themselves in the most complex manner, we require global standardization efforts and patient cohorts for comparative investigations.

We have reviewed the knowledge about molecular mechanisms underlying POD and POCD and described many biomarkers associated with these postoperative complications, and it is clear that postoperative delirium and cognitive dysfunction are multifactorial conditions. Among the identified pathomechanisms, some biomarkers were common, such as elevation of TNF- $\alpha$, interleukin- $1 \beta$, interleukin-6, interleukin-8, interleukin-10, CRP, S100B, matrix metalloproteinase-9, BDNF, copeptin and cortisol levels as well as presence of ApoE $\varepsilon 4$ allele. The application of integrated

\section{References}

Abbas, A., Aukrust, P., Dahl, T. B., Bjerkeli, V., Sagen, E. B. L., Michelsen, A., et al. (2012). High levels of S100A12 are associated with recent plaque symptomatology in patients with carotid atherosclerosis. Stroke 43, 1347-1353. doi: 10.1161/STROKEAHA.111.642256

Abelha, F. J., Fernandes, V., Botelho, M., Santos, P., Santos, A., Machado, J. C., et al. (2012). Apolipoprotein E e4 allele does not increase the risk of early postoperative delirium after major surgery. J. Anesth. 26, 412-421. doi: 10. 1007/s00540-012-1326-5

Abildstrom, H., Christiansen, M., Siersma, V. D., and Rasmussen, L. S. (2004). Apolipoprotein E genotype and cognitive dysfunction after noncardiac surgery. Anesthesiology 101, 855-861. doi: 10.1097/00000542-20041000000009

Abildstrom, H., Rasmussen, L. S., Rentowl, P., Hanning, C. D., Rasmussen, H., Kristensen, P. A., et al. (2000). Cognitive dysfunction 1-2 years after noncardiac surgery in the elderly. ISPOCD group. International study of postoperative cognitive dysfunction. Acta Anaesthesiol. Scand. 44, 1246-1251. doi: 10.1034/j.1399-6576.2000.441010.x

Acheson, A., Conover, J. C., Fandl, J. P., DeChiara, T. M., Russell, M., Thadani, A., et al. (1995). A BDNF autocrine loop in adult sensory neurons prevents cell death. Nature 374, 450-453. doi: 10.1038/374450a 0

Adamis, D., Lunn, M., Martin, F. C., Treloar, A., Gregson, N., Hamilton, G., et al. (2009). Cytokines and IGF-I in delirious and non-delirious acutely ill older medical inpatients. Age Ageing 38, 326-332. doi: 10.1093/ageing/afp014

Adamis, D., Treloar, A., Martin, F. C., Gregson, N., Hamilton, G., and Macdonald, A. J. D. (2007). APOE and cytokines as biological markers for recovery of prevalent delirium in elderly medical inpatients. Int. J. Geriatr. Psychiatry 22, 688-694. doi: 10.1002/gps.1732

Adams Wilson, J. R., Morandi, A., Girard, T. D., Thompson, J. L., Boomershine, C. S., Shintani, A. K., et al. (2012). The association of the kynurenine pathway of tryptophan metabolism with acute brain dysfunction during critical illness*. Crit. Care Med. 40, 835-841. doi: 10.1097/CCM.0b013e3182 $36 f 62 d$ systems biology approaches may elucidate the unknown pathomechanisms contributing to $\mathrm{POD} / \mathrm{POCD}$ origin and progression. Combining experimental measurements, imaging techniques and mathematical/computational modeling can give a potential to reconstruct the underlying network of molecular interactions and predict reliable biomarkers of postoperative delirium and cognitive dysfunction.

\section{PubMed Search Strategy}

We reviewed the pertinent literature retrieved by a search in the PubMed database (on November 20, 2014) using the following query: "(biomarker OR marker) AND [(postoperative delirium) OR delirium OR (postoperative cognitive dysfunction) OR POCD] AND (hasabstract[text] AND Humans[Mesh]) NOT (Alzheimer OR Parkinson)". The search yielded 254 publications. The ones cited in the review are those that, in the author's view, make a substantial contribution to the knowledge about existing and potential biomarkers of POD/POCD.

\section{Funding}

The research leading to these results has received funding from the framework of the EU-funded FP7 research program: BioCog (Biomarker Development for Postoperative Cognitive Impairment in the Elderly): www.biocog.eu

Ader, R., Cohen, N., and Felten, D. (1995). Psychoneuroimmunology: interactions between the nervous system and the immune system. Lancet 345, 99-103. doi: 10.1016/s0140-6736(95)90066-7

Alagiakrishnan, K., and Wiens, C. A. (2004). An approach to drug induced delirium in the elderly. Postgrad. Med. J. 80, 388-393. doi: 10.1136/pgmj.2003. 017236

American Psychiatric Association. (2013). Diagnostic and Statistical Manual of Mental Disorders. 5th Edn. Arlington, VA: American Psychiatric Publishing, Inc.

Anagnostaras, S. G., Murphy, G. G., Hamilton, S. E., Mitchell, S. L., Rahnama, N. P., Nathanson, N. M., et al. (2003). Selective cognitive dysfunction in acetylcholine M1 muscarinic receptor mutant mice. Nat. Neurosci. 6, 51-58. doi: 10.1038/nn992

Andre, R., Wheeler, R. D., Collins, P. D., Luheshi, G. N., Pickering-Brown, S., Kimber, I., et al. (2003). Identification of a truncated IL-18R $\beta$ mRNA: a putative regulator of IL-18 expressed in rat brain. J. Neuroimmunol. 145, 40-45. doi: 10. 1016/j.jneuroim.2003.09.005

Ansaloni, L., Catena, F., Chattat, R., Fortuna, D., Franceschi, C., Mascitti, P., et al (2010). Risk factors and incidence of postoperative delirium in elderly patients after elective and emergency surgery. Br. J. Surg. 97, 273-280. doi: 10.1002/bjs. 6843

Bai, S., Liu, S., Guo, X., Qin, Z., Wang, B., Li, X., et al. (2009). Proteome analysis of biomarkers in the cerebrospinal fluid of neuromyelitis optica patients. Mol. Vis. 15, 1638-1648.

Balan, S., Leibovitz, A., Zila, S. O., Ruth, M., Chana, W., Yassica, B., et al. (2003). The relation between the clinical subtypes of delirium and the urinary level of 6-SMT. J. Neuropsychiatry Clin. Neurosci. 15, 363-366. doi: 10.1176/appi. neuropsych.15.3.363

Barrientos, R. M., Hein, A. M., Frank, M. G., Watkins, L. R., and Maier, S. F. (2012). Intracisternal interleukin-1 receptor antagonist prevents postoperative cognitive decline and neuroinflammatory response in aged rats. J. Neurosci. 32, 14641-14648. doi: 10.1523/JNEUROSCI.2173-12.2012

Bassil, F., Fernagut, P. O., Bezard, E., and Meissner, W. G. (2014). Insulin, IGF-1 and GLP-1 signaling in neurodegenerative disorders: targets for disease 
modification? Prog. Neurobiol. 118, 1-18. doi: 10.1016/j.pneurobio.2014. 02.005

Beloosesky, Y., Grinblat, J., Pirotsky, A., Weiss, A., and Hendel, D. (2004). Different C-reactive protein kinetics in post-operative hip-fractured geriatric patients with and without complications. Gerontology 50, 216-222. doi: 10. $1159 / 000078350$

Berger, R. P., Adelson, P. D., Pierce, M. C., Dulani, T., Cassidy, L. D., and Kochanek, P. M. (2005). Serum neuron-specific enolase, S100B and myelin basic protein concentrations after inflicted and noninflicted traumatic brain injury in children. J. Neurosurg. 103, 61-68. doi: 10.3171/ped.2005.103.1.0061

Bi, Y., Liu, S., Yu, X., Wang, M., and Wang, Y. (2014). Adaptive and regulatory mechanisms in aged rats with postoperative cognitive dysfunction. Neural Regen. Res. 9, 534-539. doi: 10.4103/1673-5374.130084

Bianchi, R., Adami, C., Giambanco, I., and Donato, R. (2007). S100B binding to RAGE in microglia stimulates COX-2 expression. J. Leukoc. Biol. 81, 108-118. doi: $10.1189 / \mathrm{jlb} .0306198$

Bisschop, P. H., de Rooij, S. E., Zwinderman, A. H., van Oosten, H. E., and van Munster, B. C. (2011). Cortisol, insulin and glucose and the risk of delirium in older adults with hip fracture. J. Am. Geriatr. Soc. 59, 1692-1696. doi: 10.1111/j. 1532-5415.2011.03575.x

Boraschi, D., Lucchesi, D., Hainzl, S., Leitner, M., Maier, E., Mangelberger, D., et al. (2011). IL-37: a new anti-inflammatory cytokine of the IL-1 family. Eur. Cytokine Netw. 22, 127-147. doi: 10.1684/ecn.2011.0288

Borovikova, L. V., Ivanova, S., Zhang, M., Yang, H., Botchkina, G. I., Watkins, L. R., et al. (2000). Vagus nerve stimulation attenuates the systemic inflammatory response to endotoxin. Nature 405, 458-462. doi: 10. $1038 / 35013070$

Bossù, P., Ciaramella, A., Salani, F., Bizzoni, F., Varsi, E., Di Iulio, F., et al. (2008). Interleukin-18 produced by peripheral blood cells is increased in Alzheimer's disease and correlates with cognitive impairment. Brain Behav. Immun. 22, 487-492. doi: 10.1016/j.bbi.2007.10.001

Bossù, P., Ciaramella, A., Salani, F., Vanni, D., Palladino, I., Caltagirone, C., et al. (2010). Interleukin-18, from neuroinflammation to Alzheimer's disease. Curr. Pharm. Des. 16, 4213-4224. doi: 10.2174/138161210794519147

Bryson, G. L., Wyand, A., Wozny, D., Rees, L., Taljaard, M., and Nathan, H. (2011). Une étude de cohorte prospective évaluant les associations entre le delirium, le dysfonctionnement cognitif postopératoire et le génotype de l'apolipoprotéine E après une chirurgie ouverte de l'aorte. Can. J. Anesth. Can. D'anesthésie 58, 246-255. doi: 10.1007/s12630-010-9446-6

Brzezinski, A. (1997). Melatonin in humans. N. Engl. J. Med. 336, 186-195. doi: 10. 1056/NEJM199701163360306

Burkhart, C. S., Dell-Kuster, S., Gamberini, M., Moeckli, A., Grapow, M., Filipovic, M., et al. (2010). Modifiable and nonmodifiable risk factors for postoperative delirium after cardiac surgery with cardiopulmonary bypass. J. Cardiothorac. Vasc. Anesth. 24, 555-559. doi: 10.1053/j.jvca.2010.01.003

Calne, D. B., Mcgeer, E., Eisen, A., and Spencer, P. (1986). Alzheimer's disease, Parkinson's disease and motoneurone disease: abiotropic interaction between agening and environment? Lancet 328, 1067-1070. doi: 10.1016/s01406736(86)90469-1

Cao, L., Wang, K., Gu, T., Du, B., and Song, J. (2014). Association between APOE epsilon 4 allele and postoperative cognitive dysfunction: a meta-analysis. Int. J. Neurosci. 124, 478-485. doi: 10.3109/00207454.2013.860601

Cape, E., Hall, R. J., van Munster, B. C., de Vries, A., Howie, S. E. M., Pearson, A., et al. (2014). Cerebrospinal fluid markers of neuroinflammation in delirium: a role for interleukin-1 $\beta$ in delirium after hip fracture. J. Psychosom. Res. 77, 219-225. doi: 10.1016/j.jpsychores.2014.06.014

Carrié, A., Jun, L., Bienvenu, T., Vinet, M. C., McDonell, N., Couvert, P., et al. (1999). A new member of the IL-1 receptor family highly expressed in hippocampus and involved in X-linked mental retardation. Nat. Genet. 23, 25-31. doi: 10.1038/12623

Cerejeira, J., Batista, P., Nogueira, V., Vaz-Serra, A., and Mukaetova-Ladinska, E. B. (2013). The stress response to surgery and postoperative delirium: evidence of hypothalamic-pituitary-adrenal axis hyperresponsiveness and decreased suppression of the GH/IGF-1 Axis. J. Geriatr. Psychiatry Neurol. 26, 185-194. doi: 10.1177/0891988713495449

Cerejeira, J. M. S., Nogueira, V., Luís, P., Vaz-Serra, A., and Mukaetova-Ladinska, E. B. (2012). The cholinergic system and inflammation: common pathways in delirium pathophysiology. J. Am. Geriatr. Soc. 60, 669-675. doi: 10.1111/j.15325415.2011.03883.x
Chandel, N. S., Trzyna, W. C., McClintock, D. S., and Schumacker, P. T. (2000). Role of oxidants in NF-kappa B activation and TNF-alpha gene transcription induced by hypoxia and endotoxin. J. Immunol. 165, 1013-1021. doi: 10. 4049/jimmunol.165.2.1013

Chang, K. A., Kim, H. J., and Suh, Y. H. (2012). The role of S100a9 in the pathogenesis of Alzheimer's disease: the therapeutic effects of S100a9 knockdown or knockout. Neurodegener. Dis. 10, 27-29. doi: 10. $1159 / 000333781$

Chang, Y.-L., Tsai, Y.-F., Lin, P.-J., Chen, M.-C., and Liu, C.-Y. (2008). Prevalence and risk factors for postoperative delirium in a cardiovascular intensive care unit. Am. J. Crit. Care 17, 567-575.

Cheng, Q., Wang, J., Wu, A., Zhang, R., Li, L., and Yue, Y. (2013). Can urinary excretion rate of 8-isoprostrane and malonaldehyde predict postoperative cognitive dysfunction in aging? Neurol. Sci. 34, 1665-1669. doi: $10.1007 /$ s10072-013-1314-z

Chiaretti, A., Piastra, M., Polidori, G., Di Rocco, C., Caresta, E., Antonelli, A., et al. (2003). Correlation between neurotrophic factor expression and outcome of children with severe traumatic brain injury. Intensive Care Med. 29, 1329-1338. doi: 10.1007/s00134-003-1852-6

Cho, Y.-W., Motamedi, G. K., Laufenberg, I., Sohn, S.-I., Lim, J.-G., Lee, H., et al. (2003). A Korean kindred with autosomal dominant nocturnal frontal lobe epilepsy and mental retardation. Arch. Neurol. 60, 1625-1632. doi: 10. 1001/archneur.60.11.1625

Cibelli, M., Fidalgo, A. R., Terrando, N., Ma, D., Monaco, C., Feldmann, M., et al. (2010). Role of interleukin-1beta in postoperative cognitive dysfunction. Ann Neurol. 68, 360-368. doi: 10.1002/ana.22082

Colkesen, Y., Giray, S., Ozenli, Y., Sezgin, N., and Coskun, I. (2013). Relation of serum cortisol to delirium occurring after acute coronary syndromes. Am. J. Emerg. Med. 31, 161-165. doi: 10.1016/j.ajem.2012.07.001

Cong, W. N., Wang, R., Cai, H., Daimon, C. M., Scheibye-Knudsen, M., Bohr, V. A., et al. (2013). Long-term artificial sweetener Acesulfame Potassium treatment alters neurometabolic functions in C57BL/6J mice. PLoS One 8:e70257. doi: 10.1371/journal.pone.0070257

Control Prevention Centers for Disease (2010). National hospital discharge survey: procedures by selected patient characteristics. Number and percentage with and without procedures. CDC/NCHS Natl. Hosp. Disch. Surv. Available online at: http://www.cdc.gov/nchs/data/nhds/4procedures/ 2010pro_numberpercentage.pdf

Costelloe, C., Watson, M., Murphy, A., McQuillan, K., Loscher, C., Armstrong, M. E., et al. (2008). IL-1F5 mediates anti-inflammatory activity in the brain through induction of IL-4 following interaction with SIGIRR/TIR8. J. Neurochem. 105, 1960-1969. doi: 10.1111/j.1471-4159.2008. 05304.x

Cras, P., Kawai, M., Lowery, D., Gonzalez-DeWhitt, P., Greenberg, B., and Perry, G. (1991). Senile plaque neurites in Alzheimer disease accumulate amyloid precursor protein. Proc. Natl. Acad. Sci. U S A 88, 7552-7556. doi: 10. 1073/pnas.88.17.7552

Culley, D. J., Baxter, M., Yukhananov, R., and Crosby, G. (2003). The memory effects of general anesthesia persist for weeks in young and aged rats. Anesth. Analg. 96, 1004-1009. doi: 10.1213/01.ane.0000052712.67 573.12

Deguchi, A., Soh, J.-W., Li, H., Pamukcu, R., Thompson, W. J., and Weinstein, I. B. (2002). Vasodilator-stimulated phosphoprotein (VASP) phosphorylation provides a biomarker for the action of exisulind and related agents that activate protein kinase G. Mol. Cancer Ther. 1, 803-809.

Deiner, S., and Silverstein, J. H. (2009). Postoperative delirium and cognitive dysfunction. Br. J. Anaesth. 103(Suppl.), i41-i46. doi: 10.1093/bja/aep291

de Jonghe, A., van Munster, B. C., Fekkes, D., van Oosten, H. E., and de Rooij, S. E. (2012). The tryptophan depletion theory in delirium: not confirmed in elderly hip fracture patients. Psychosomatics 53, 236-243. doi: 10.1016/j.psym.2011. 09.009

de Jonghe, A., van Munster, B. C., Goslings, J. C., Kloen, P., van Rees, C., Wolvius, R., et al. (2014). Effect of melatonin on incidence of delirium among patients with hip fracture: a multicentre, double-blind randomized controlled trial. CMAJ 186, E547-E556. doi: 10.1503/cmaj. 140495

Dixson, L., Walter, H., Schneider, M., Erk, S., Schäfer, A., Haddad, L., et al. (2014). Identification of gene ontologies linked to prefrontal-hippocampal functional coupling in the human brain. Proc. Natl. Acad. Sci. U S A 111, 9657-9662. doi: $10.1073 /$ pnas. 1404082111 
Drake, P. M., Cho, W., Li, B., Prakobphol, A., Johansen, E., Anderson, N. L., et al. (2010). Sweetening the pot: adding glycosylation to the biomarker discovery equation. Clin. Chem. 56, 223-236. doi: 10.1373/clinchem.2009.136333

Eckert, T., Tang, C., and Eidelberg, D. (2007). Assessment of the progression of Parkinson's disease: a metabolic network approach. Lancet Neurol. 6, 926-932. doi: 10.1016/S1474-4422(07)70245-4

Elie, M., Cole, M. G., Primeau, F. J., and Bellavance, F. (1998). Delirium risk factors in elderly hospitalized patients. J. Gen. Intern. Med. 13, 204-212. doi: 10.1046/j. 1525-1497.1998.00047.x

Ely, E. W., Girard, T. D., Shintani, A. K., Jackson, J. C., Gordon, S. M., Thomason, J. W. W., et al. (2007). Apolipoprotein E4 polymorphism as a genetic predisposition to delirium in critically ill patients. Crit. Care Med. 35, 112-117. doi: 10.1097/01.ccm.0000251925.18961.ca

Everitt, B. J., and Robbins, T. W. (1997). Central cholinergic systems and cognition. Annu. Rev. Psychol. 48, 649-684. doi: 10.1146/annurev.psych.48. 1.649

Fasano, A. (2011). Zonulin and its regulation of intestinal barrier function: the biological door to inflammation, autoimmunity and cancer. Physiol. Rev. 91, 151-175. doi: 10.1152/physrev.00003.2008

Fasano, A., Not, T., Wang, W., Uzzau, S., Berti, I., Tommasini, A., et al. (2000). Zonulin, a newly discovered modulator of intestinal permeability and its expression in coeliac disease. Lancet 355, 1518-1519. doi: 10.1016/s01406736(00)02169-3

Feng, Y., Niu, T., Xing, H., Xu, X., Chen, C., Peng, S., et al. (2004). A common haplotype of the nicotine acetylcholine receptor alpha 4 subunit gene is associated with vulnerability to nicotine addiction in men. Am. J. Hum. Genet. 75, 112-121. doi: 10.1086/422194

Field, R. H., Gossen, A., and Cunningham, C. (2012). Prior pathology in the basal forebrain cholinergic system predisposes to inflammation-induced working memory deficits: reconciling inflammatory and cholinergic hypotheses of delirium. J. Neurosci. 32, 6288-6294. doi: 10.1523/JNEUROSCI.467311.2012

Finfer, S., Chittock, D. R., Su, S. Y.-S., Blair, D., Foster, D., Dhingra, V., et al. (2009). Intensive versus conventional glucose control in critically ill patients. N. Engl. J. Med. 360, 1283-1297. doi: 10.1056/NEJMoa0810625

Fisher, A. (2008). Cholinergic treatments with emphasis on $\mathrm{m} 1$ muscarinic agonists as potential disease-modifying agents for Alzheimer's disease. Neurotherapeutics 5, 433-442. doi: 10.1016/j.nurt.2008.05.002

Flacker, J. M., Cummings, V., Mach, J. R., Bettin, K., Kiely, D. K., and Wei, J. (1998). The association of serum anticholinergic activity with delirium in elderly medical patients. Am. J. Geriatr. Psychiatry 6, 31-41. doi: 10. 1097/00019442-199800610-00005

Flacker, J. M., and Lipsitz, L. A. (1999). Serum anticholinergic activity changes with acute illness in elderly medical patients. J. Gerontol. A Biol. Sci. Med. Sci. 54, M12-M16. doi: 10.1093/gerona/54.1.m12

Foell, D., Frosch, M., Sorg, C., and Roth, J. (2004). Phagocyte-specific calciumbinding S100 proteins as clinical laboratory markers of inflammation. Clin. Chim. Acta 344, 37-51. doi: 10.1016/j.cccn.2004.02.023

Fox, C., Smith, T., Maidment, I., Chan, W.-Y., Bua, N., Myint, P. K., et al. (2014). Effect of medications with anti-cholinergic properties on cognitive function, delirium, physical function and mortality: a systematic review. Age Ageing 43, 604-615. doi: 10.1093/ageing/afu096

Frost, R. A., Nystrom, G. J., and Lang, C. H. (2003). Tumor necrosis factor-alpha decreases insulin-like growth factor-I messenger ribonucleic acid expression in $\mathrm{C} 2 \mathrm{C} 12$ myoblasts via a Jun N-terminal kinase pathway. Endocrinology 144, 1770-1779. doi: 10.1210/en.2002-220808

Fujita, K. A., Ostaszewski, M., Matsuoka, Y., Ghosh, S., Glaab, E., Trefois, C., et al. (2014). Integrating pathways of parkinson's disease in a molecular interaction map. Mol. Neurobiol. 49, 88-102. doi: 10.1007/s12035-013-8489-4

Girard, T. D., Ware, L. B., Bernard, G. R., Pandharipande, P. P., Thompson, J. L., Shintani, A. K., et al. (2012). Associations of markers of inflammation and coagulation with delirium during critical illness. Intensive Care Med. 38, 1965-1973. doi: 10.1007/s00134-012-2678-x

Grandi, C., Tomasi, C. D., Fernandes, K., Stertz, L., Kapczinski, F., Quevedo, J., et al. (2011). Brain-derived neurotrophic factor and neuron-specific enolase, but not $S 100 \beta$, levels are associated to the occurrence of delirium in intensive care unit patients. J. Crit. Care 26, 133-137. doi: 10.1016/j.jcrc.2010. 10.006
Greene, N. H., Attix, D. K., Weldon, B. C., Smith, P. J., McDonagh, D. L., and Monk, T. G. (2009). Measures of executive function and depression identify patients at risk for postoperative delirium. Anesthesiology 110, 788-795. doi: 10 . 1097/aln.0b013e31819b5ba6

Gross, A. L., Jones, R. N., Habtemariam, D. A., Fong, T. G., Tommet, D., Quach, L., et al. (2012). Delirium and long-term cognitive trajectory among persons with dementia. Arch. Intern. Med. 172, 1324-1331. doi: 10.1001/archinternmed. 2012.3414

Gunther, M. L., Morandi, A., Krauskopf, E., Pandharipande, P., Girard, T. D., Jackson, J. C., et al. (2012). The association between brain volumes, delirium duration and cognitive outcomes in intensive care unit survivors. Crit. Care Med. 40, 2022-2032. doi: 10.1097/CCM.0b013e318250acc0

Gutcher, I., Urich, E., Wolter, K., Prinz, M., and Becher, B. (2006). Interleukin 18 -independent engagement of interleukin 18 receptor-alpha is required for autoimmune inflammation. Nat. Immunol. 7, 946-953. doi: 10.1038/ni1377

Hasselmo, M. E. (1995). Neuromodulation and cortical function: modeling the physiological basis of behavior. Behav. Brain Res. 67, 1-27. doi: 10.1016/01664328(94)00113-t

Hatano, Y., Narumoto, J., Shibata, K., Matsuoka, T., Taniguchi, S., Hata, Y., et al. (2013). White-matter hyperintensities predict delirium after cardiac surgery. Am. J. Geriatr. Psychiatry 21, 938-945. doi: 10.1016/j.jagp.2013.01.061

Hersch, S. M., Gutekunst, C. A., Rees, H. D., Heilman, C. J., and Levey, A. I. (1994). Distribution of m1-m4 muscarinic receptor proteins in the rat striatum: light and electron microscopic immunocytochemistry using subtype-specific antibodies. J. Neurosci. 14, 3351-3363.

Hirose, S., Iwata, H., Akiyoshi, H., Kobayashi, K., Ito, M., Wada, K., et al. (1999). A novel mutation of CHRNA4 responsible for autosomal dominant nocturnal frontal lobe epilepsy. Neurology 53, 1749-1753. doi: 10.1212/wnl.53.8.1749

Hshieh, T. T., Fong, T. G., Marcantonio, E. R., and Inouye, S. K. (2008). Cholinergic deficiency hypothesis in delirium: a synthesis of current evidence. J. Gerontol. A Biol. Sci. Med. Sci. 63, 764-772. doi: 10.1093/gerona/63.7.764

Huang, E. J., and Reichardt, L. F. (2001). Neurotrophins: roles in neuronal development and function. Annu. Rev. Neurosci. 24, 677-736. doi: 10. 1146/annurev.neuro.24.1.677

Huat, T. J., Khan, A. A., Pati, S., Mustafa, Z., Abdullah, J. M., and Jaafar, H. (2014). IGF-1 enhances cell proliferation and survival during early differentiation of mesenchymal stem cells to neural progenitor-like cells. BMC Neurosci. 15:91. doi: 10.1186/1471-2202-15-91

Hudetz, J. A., Gandhi, S. D., Iqbal, Z., Patterson, K. M., and Pagel, P. S. (2011). Elevated postoperative inflammatory biomarkers are associated with short- and medium-term cognitive dysfunction after coronary artery surgery. J. Anesth. 25, 1-9. doi: 10.1007/s00540-010-1042-y

Hudetz, J. A., Patterson, K. M., Byrne, A. J., Pagel, P. S., and Warltier, D. C. (2009). Postoperative delirium is associated with postoperative cognitive dysfunction at one week after cardiac surgery with cardiopulmonary bypass. Psychol. Rep. 105, 921-932. doi: 10.2466/pr0.105.3.921-932

Ignatius, M. J., Gebicke-Härter, P. J., Skene, J. H., Schilling, J. W., Weisgraber, K. H., Mahley, R. W., et al. (1986). Expression of apolipoprotein E during nerve degeneration and regeneration. Proc. Natl. Acad. Sci. U S A 83, 1125-1129. doi: $10.1073 /$ pnas.83.4.1125

Inouye, S. K. (2006). Delirium in older persons. N. Engl. J. Med. 354, 1157-1165. doi: 10.1056/NEJMra052321

Inouye, S. K., van Dyck, C. H., Alessi, C. A., Balkin, S., Siegal, A. P., and Horwitz, R. I. (1990). Clarifying confusion: the confusion assessment method: a new method for detection of delirium. Ann. Intern. Med. 113, 941-948. doi: 10. 7326/0003-4819-113-12-941

Jackson, J. C., Gordon, S. M., Hart, R. P., Hopkins, R. O., and Ely, E. W. (2004). The association between delirium and cognitive decline: a review of the empirical literature. Neuropsychol. Rev. 14, 87-98. doi: 10.1023/b:nerv. 0000028080.39602 .17

Jin, T., Hu, L. S., Chang, M., Wu, J., Winblad, B., and Zhu, J. (2007). Proteomic identification of potential protein markers in cerebrospinal fluid of GBS patients. Eur. J. Neurol. 14, 563-568. doi: 10.1111/j.1468-1331.2007.01761.x

Kang, J., Lemaire, H. G., Unterbeck, A., Salbaum, J. M., Masters, C. L., Grzeschik, K. H., et al. (1987). The precursor of Alzheimer's disease amyloid A4 protein resembles a cell-surface receptor. Nature 325, 733-736. doi: 10.1038/325733a0

Karyekar, C. S., Fasano, A., Raje, S., Lu, R., Dowling, T. C., and Eddington, N. D. (2003). Zonula occludens toxin increases the permeability of molecular weight 
markers and chemotherapeutic agents across the bovine brain microvessel endothelial cells. J. Pharm. Sci. 92, 414-423. doi: 10.1002/jps.10310

Katan, M., and Christ-Crain, M. (2010). The stress hormone copeptin: a new prognostic biomarker in acute illness. Swiss Med. Wkly. 140:w13101. doi: 10. 4414/smw.2010.13101

Kazmierski, J., Banys, A., Latek, J., Bourke, J., and Jaszewski, R. (2013). Cortisol levels and neuropsychiatric diagnosis as markers of postoperative delirium: a prospective cohort study. Crit. Care 17:R38. doi: 10.1186/cc12548

Kazmierski, J., Banys, A., Latek, J., Bourke, J., and Jaszewski, R. (2014a). Raised IL- 2 and TNF- $\alpha$ concentrations are associated with postoperative delirium in patients undergoing coronary-artery bypass graft surgery. Int. Psychogeriatr. 26, 845-855. doi: 10.1017/s1041610213002378

Kazmierski, J., Banys, A., Latek, J., Bourke, J., Jaszewski, R., Sobow, T., et al. (2014b). Mild cognitive impairment with associated inflammatory and cortisol alterations as independent risk factor for postoperative delirium. Dement. Geriatr. Cogn. Disord. 38, 65-78. doi: 10.1159/000357454

Khan, B. A., Zawahiri, M., Campbell, N. L., and Boustani, M. A. (2011). Biomarkers for delirium-a review. J. Am. Geriatr. Soc. 59(Suppl. 2), S256-S261. doi: 10. 1111/j.1532-5415.2011.03702.x

Kohannim, O., Hua, X., Hibar, D. P., Lee, S., Chou, Y.-Y. Y., Toga, A. W., et al. (2010). Boosting power for clinical trials using classifiers based on multiple biomarkers. Neurobiol. Aging 31, 1429-1442. doi: 10.1016/j.neurobiolaging. 2010.04.022

Kong, F.-J., Ma, L.-L., Zhang, H.-H., and Zhou, J.-Q. (2015). Alpha 7 nicotinic acetylcholine receptor agonist GTS-21 mitigates isoflurane-induced cognitive impairment in aged rats. J. Surg. Res. 194, 255-261. doi: 10.1016/j.jss.2014. 09.043

Koning, J. P., Vehof, J., Burger, H., Wilffert, B., Al Hadithy, A., Alizadeh, B., et al. (2012). Association of two DRD2 gene polymorphisms with acute and tardive antipsychotic-induced movement disorders in young Caucasian patients. Psychopharmacology (Berl) 219, 727-736. doi: 10.1007/s00213-0112394-1

Kosar, C. M., Tabloski, P. A., Travison, T. G., Jones, R. N., Schmitt, E. M., Puelle, M. R., et al. (2014). Effect of preoperative pain and depressive symptoms on the risk of postoperative delirium: a prospective cohort study. Lancet Psychiatry 1, 431-436. doi: 10.1016/s2215-0366(14)00006-6

Kowall, N. W., Beal, M. F., Busciglio, J., Duffy, L. K., and Yankner, B. A. (1991). An in vivo model for the neurodegenerative effects of beta amyloid and protection by substance P. Proc. Natl. Acad. Sci. U S A 88, 7247-7251. doi: 10.1073/pnas. 88.16.7247

Kukreti, R., Tripathi, S., Bhatnagar, P., Gupta, S., Chauhan, C., Kubendran, S., et al. (2006). Association of DRD2 gene variant with schizophrenia. Neurosci. Lett. 392, 68-71. doi: 10.1016/j.neulet.2005.08.059

Lambert, N. M., and Hartsough, C. S. (1998). Prospective study of tobacco smoking and substance dependencies among samples of ADHD and nonADHD participants. J. Learn. Disabil. 31, 533-544. doi: 10.1177/002221949803 100603

Le, Y., Liu, S., Peng, M., Tan, C., Liao, Q., Duan, K., et al. (2014). Aging differentially affects the loss of neuronal dendritic spine, neuroinflammation and memory impairment at rats after surgery. PLoS One 9:e106837. doi: 10. 1371/journal.pone.0106837

Lemstra, A. W., Kalisvaart, K. J., Vreeswijk, R., van Gool, W. A., and Eikelenboom, P. (2008). Pre-operative inflammatory markers and the risk of postoperative delirium in elderly patients. Int. J. Geriatr. Psychiatry 23, 943-948. doi: 10. 1002/gps.2015

Leung, J. M., Sands, L. P., Mullen, E. A., Wang, Y., and Vaurio, L. (2005). Are preoperative depressive symptoms associated with postoperative delirium in geriatric surgical patients? J. Gerontol. A Biol. Sci. Med. Sci. 60, 1563-1568. doi: 10.1093/gerona/60.12.1563

Leung, J. M., Sands, L. P., Wang, Y., Poon, A., Kwok, P., Kane, J. P., et al. (2007). Apolipoprotein E e4 allele increases the risk of early postoperative delirium in older patients undergoing noncardiac surgery. Anesthesiology 107, 406-411. doi: 10.1097/01.anes.0000278905.07899.df

Levey, A. I. (1996). Muscarinic acetylcholine receptor expression in memory circuits: implications for treatment of Alzheimer disease. Proc. Natl. Acad. Sci. U S A 93, 13541-13546. doi: 10.1073/pnas.93.24.13541

Li, M. D., Beuten, J., Ma, J. Z., Payne, T. J., Lou, X.-Y., Garcia, V., et al. (2005). Ethnic- and gender-specific association of the nicotinic acetylcholine receptor alpha4 subunit gene (CHRNA4) with nicotine dependence. Hum. Mol. Genet. 14, 1211-1219. doi: 10.1093/hmg/ddi132

Li, X., Wen, D.-X., Zhao, Y.-H., Hang, Y.-N., and Mandell, M. S. (2013b). Increase of beta-amyloid and C-reactive protein in liver transplant recipients with postoperative cognitive dysfunction. Hepatobiliary Pancreat. Dis. Int. 12, 370-376. doi: 10.1016/s1499-3872(13)60058-2

Li, Y. C., Xi, C. H., An, Y. F., Dong, W. H., and Zhou, M. (2012). Perioperative inflammatory response and protein S-100 $\beta$ concentrations-relationship with post-operative cognitive dysfunction in elderly patients. Acta Anaesthesiol. Scand. 56, 595-600. doi: 10.1111/j.1399-6576.2011.02616.x

Li, R. L., Zhang, Z. Z., Peng, M., Wu, Y., Zhang, J. J., Wang, C. Y., et al. (2013a). Postoperative impairment of cognitive function in old mice: a possible role for neuroinflammation mediated by HMGB1, S100B and RAGE. J. Surg. Res. 185, 815-824. doi: 10.1016/j.jss.2013.06.043

Lili, X., Zhiyong, H., and Jianjun, S. (2013). A preliminary study of the effects of ulinastatin on early postoperative cognition function in patients undergoing abdominal surgery. Neurosci. Lett. 541, 15-19. doi: 10.1016/j.neulet.2013. 02.008

Liu, P., Li, Y., Wang, X., Zou, X., Zhang, D., Wang, D., et al. (2013). High serum interleukin-6 level is associated with increased risk of delirium in elderly patients after noncardiac surgery: a prospective cohort study. Chin. Med. J. (Engl) 126, 3621-3627. doi: 10.3760/cma.j.issn.0366-6999.201 30211

Lu, R., Wang, W., Uzzau, S., Vigorito, R., Zielke, H. R., and Fasano, A. (2000). Affinity purification and partial characterization of the zonulin/zonula occludens toxin (Zot) receptor from human brain. J. Neurochem. 74, 320-326. doi: 10.1046/j.1471-4159.2000.0740320.x

Lu, S.-M., Yu, C.-J., Liu, Y.-H., Dong, H.-Q., Zhang, X., Zhang, S.-S., et al. (2015). S100A8 contributes to postoperative cognitive dysfunction in mice undergoing tibial fracture surgery by activating the TLR4/MyD88 pathway. Brain Behav. Immun. 44, 221-234. doi: 10.1016/j.bbi.2014.10.011

Lupien, S. J., Gillin, C. J., and Hauger, R. L. (1999). Working memory is more sensitive than declarative memory to the acute effects of corticosteroids: a doseresponse study in humans. Behav. Neurosci. 113, 420-430. doi: 10.1037/07357044.113.3.420

Macdonald, A., Adamis, D., Treloar, A., and Martin, F. (2007). C-reactive protein levels predict the incidence of delirium and recovery from it. Age Ageing 36, 222-225. doi: 10.1093/ageing/afl121

Mach, J. R., Dysken, M. W., Kuskowski, M., Richelson, E., Holden, L., and Jilk, K. M. (1995). Serum anticholinergic activity in hospitalized older persons with delirium: a preliminary study. J. Am. Geriatr. Soc. 43, 491-495. doi: 10.1111/j. 1532-5415.1995.tb06094.x

Makoff, A. J., Graham, J. M., Arranz, M. J., Forsyth, J., Li, T., Aitchison, K. J., et al. (2000). Association study of dopamine receptor gene polymorphisms with drug-induced hallucinations in patients with idiopathic Parkinson's disease. Pharmacogenetics 10, 43-48. doi: 10.1097/00008571-200002000-00006

Manenschijn, L., van Rossum, E. F. C., Jetten, A. M., de Rooij, S. E., and van Munster, B. C. (2011). Glucocorticoid receptor haplotype is associated with a decreased risk of delirium in the elderly. Am. J. Med. Genet. B Neuropsychiatr. Genet. 156B, 316-321. doi: 10.1002/ajmg.b.31165

Mantovani, A., Locati, M., Polentarutti, N., Vecchi, A., and Garlanda, C. (2004). Extracellular and intracellular decoys in the tuning of inflammatory cytokines and Toll-like receptors: the new entry TIR8/SIGIRR. J. Leukoc. Biol. 75, 738-742. doi: 10.1189/jlb.1003473

Mathew, J. P., Grocott, H. P., Phillips-Bute, B., Stafford-Smith, M., Laskowitz, D. T., Rossignol, D., et al. (2003). Lower endotoxin immunity predicts increased cognitive dysfunction in elderly patients after cardiac surgery. Stroke 34, 508-513. doi: 10.1161/01.str.0000053844.09493.58

McAvay, G. J., Van Ness, P. H., Bogardus, S. T., Zhang, Y., Leslie, D. L., LeoSummers, L. S., et al. (2007). Depressive symptoms and the risk of incident delirium in older hospitalized adults. J. Am. Geriatr. Soc. 55, 684-691. doi: 10. 1111/j.1532-5415.2007.01150.x

McDonagh, D. L., Mathew, J. P., White, W. D., Phillips-Bute, B., Laskowitz, D. T., Podgoreanu, M. V., et al. (2010). Cognitive function after major noncardiac surgery, apolipoprotein E4 genotype and biomarkers of brain injury. Anesthesiology 112, 852-859. doi: 10.1097/ALN.0b013e3181d31fd7

Mick, E., Kim, J. W., Biederman, J., Wozniak, J., Wilens, T., Spencer, T., et al. (2008). Family based association study of pediatric bipolar disorder and the 
dopamine transporter gene (SLC6A3). Am. J. Med. Genet. B Neuropsychiatr. Genet. 147B, 1182-1185. doi: 10.1002/ajmg.b.30745

Minden, S. L., Carbone, L. A., Barsky, A., Borus, J. F., Fife, A., Fricchione, G. L., et al. (2005). Predictors and outcomes of delirium. Gen. Hosp. Psychiatry 27, 209-214. doi: 10.1016/j.genhosppsych.2004.12.004

Moller, J. T., Cluitmans, P., Rasmussen, L. S., Houx, P., Rasmussen, H., Canet, J., et al. (1998). Long-term postoperative cognitive dysfunction in the elderly: ISPOCD1 study. Lancet 351, 857-861. doi: 10.1016/s0140-6736(97)07382-0

Monk, T. G., Weldon, B. C., Garvan, C. W., Dede, D. E., van der Aa, M. T., Heilman, K. M., et al. (2008). Predictors of cognitive dysfunction after major noncardiac surgery. Anesthesiology 108, 18-30. doi: 10.1097/01.anes. $0000296071.19434 .1 \mathrm{e}$

Muglia, P., Vicente, A. M., Verga, M., King, N., Macciardi, F., and Kennedy, J. L. (2003). Association between the BDNF gene and schizophrenia. Mol. Psychiatry 8, 146-147. doi: 10.1038/sj.mp.4001221

Mussi, C., Ferrari, R., Ascari, S., and Salvioli, G. (1999). Importance of serum anticholinergic activity in the assessment of elderly patients with delirium. J. Geriatr. Psychiatry Neurol. 12, 82-86. doi: 10.1177/0891988799012 00208

Newman, M. F., Kirchner, J. L., Phillips-Bute, B., Gaver, V., Grocott, H., Jones, R. H., et al. (2001). Longitudinal assessment of neurocognitive function after coronary-artery bypass surgery. N. Engl. J. Med. 344, 395-402. doi: 10. 1056/NEJM200102083440601

Norton, P. A., Comunale, M. A., Krakover, J., Rodemich, L., Pirog, N., D’Amelio, A., et al. (2008). N-linked glycosylation of the liver cancer biomarker GP73. J. Cell. Biochem. 104, 136-149. doi: 10.1002/jcb.21610

Ojala, J., Alafuzoff, I., Herukka, S. K., van Groen, T., Tanila, H., and Pirttilä, T. (2009). Expression of interleukin-18 is increased in the brains of Alzheimer's disease patients. Neurobiol. Aging 30, 198-209. doi: 10.1016/j.neurobiolaging. 2007.06.006

Olivecrona, Z., and Koskinen, L. O. D. (2012). The release of S-100B and NSE in severe traumatic head injury is associated with APOE $\varepsilon 4$. Acta Neurochir. (Wien) 154, 675-680. doi: 10.1007/s00701-012-1292-6

Pandharipande, P. P., Morandi, A., Adams, J. R., Girard, T. D., Thompson, J. L., Shintani, A. K., et al. (2009). Plasma tryptophan and tyrosine levels are independent risk factors for delirium in critically ill patients. Intensive Care Med. 35, 1886-1892. doi: 10.1007/s00134-009-1573-6

Papadopoulou, E., Davilas, E., Sotiriou, V., Georgakopoulos, E., Georgakopoulou, S., Koliopanos, A., et al. (2006). Cell-free DNA and RNA in plasma as a new molecular marker for prostate and breast cancer. Ann. N Y Acad. Sci. 1075, 235-243. doi: 10.1196/annals.1368.032

Pearson-Leary, J., and McNay, E. C. (2012). Intrahippocampal administration of amyloid- $\beta(1-42)$ oligomers acutely impairs spatial working memory, insulin signaling and hippocampal metabolism. J. Alzheimers Dis. 30, 413-422. doi: 10. 3233/JAD-2012-112192

Pepys, M. B., and Hirschfield, G. M. (2003). C-reactive protein: a critical update. J. Clin. Invest. 111, 1805-1812. doi: 10.1172/jci18921

Perroud, N., Paoloni-Giacobino, A., Prada, P., Olié, E., Salzmann, A., Nicastro, R., et al. (2011). Increased methylation of glucocorticoid receptor gene (NR3C1) in adults with a history of childhood maltreatment: a link with the severity and type of trauma. Transl. Psychiatry 1:e59. doi: 10.1038/tp.2011.60

Pfister, D., Siegemund, M., Dell-Kuster, S., Smielewski, P., Rüegg, S., Strebel, S. P., et al. (2008). Cerebral perfusion in sepsis-associated delirium. Crit. Care 12:R63. doi: 10.1186/cc6891

Plaschke, K., Hill, H., Engelhardt, R., Thomas, C., Von Haken, R., Scholz, M., et al. (2007a). EEG changes and serum anticholinergic activity measured in patients with delirium in the intensive care unit. Anaesthesia 62, 1217-1223. doi: 10. 1111/j.1365-2044.2007.05255.x

Plaschke, K., Thomas, C., Engelhardt, R., Teschendorf, P., Hestermann, U., Weigand, M. A., et al. (2007b). Significant correlation between plasma and CSF anticholinergic activity in presurgical patients. Neurosci. Lett. 417, 16-20. doi: 10.1016/j.neulet.2007.02.015

Pol, R. A., van Leeuwen, B. L., Izaks, G. J., Reijnen, M. M. P. J., Visser, L., Tielliu, I. F. J., et al. (2014). C-reactive protein predicts postoperative delirium following vascular surgery. Ann. Vasc. Surg. 28, 1923-1930. doi: 10.1016/j.avsg. 2014.07.004

Praticò, C., Quattrone, D., Lucanto, T., Amato, A., Penna, O., Roscitano, C., et al. (2005). Drugs of anesthesia acting on central cholinergic system may cause post-operative cognitive dysfunction and delirium. Med. Hypotheses 65, 972-982. doi: 10.1016/j.mehy.2005.05.037

Ramlawi, B., Rudolph, J. L., Mieno, S., Feng, J., Boodhwani, M., Khabbaz, K., et al. (2006). C-Reactive protein and inflammatory response associated to neurocognitive decline following cardiac surgery. Surgery 140, 221-226. doi: 10. 1016/j.surg.2006.03.007

Rasmussen, L. S., Christiansen, M., Rasmussen, H., Kristensen, P. A., and Moller, J. T. (2000). Do blood concentrations of neurone specific enolase and S-100 beta protein reflect cognitive dysfunction after abdominal surgery? ISPOCD group. Br. J. Anaesth. 84, 242-244. doi: 10.1093/oxfordjournals.bja. a013410

Renard, P., Zachary, M. D., Bougelet, C., Mirault, M. E., Haegeman, G., Remacle, J., et al. (1997). Effects of antioxidant enzyme modulations on interleukin-1induced nuclear factor kappa B activation. Biochem. Pharmacol. 53, 149-160. doi: 10.1016/s0006-2952(96)00645-4

Rentowl, P., and Hanning, C. D. (2004). Odour identification as a marker for postoperative cognitive dysfunction: a pilot study. Anaesthesia 59, 337-343. doi: 10.1111/j.1365-2044.2004.03678.x

Rezvani, A. H., and Levin, E. D. (2001). Cognitive effects of nicotine. Biol. Psychiatry 49, 258-267. doi: 10.1016/S0006-3223(00)01094-5

Ritchie, C. W., Newman, T. H., Leurent, B., and Sampson, E. L. (2014). The association between C-reactive protein and delirium in 710 acute elderly hospital admissions. Int. Psychogeriatr. 26, 717-724. doi: 10. 1017/s1041610213002433

Robinson, T. N., Raeburn, C. D., Angles, E. M., and Moss, M. (2008). Low tryptophan levels are associated with postoperative delirium in the elderly. Am. J. Surg. 196, 670-674. doi: 10.1016/j.amjsurg.2008.07.007

Robinson, T. N., Raeburn, C. D., Tran, Z. V., Angles, E. M., Brenner, L. A., and Moss, M. (2009). Postoperative delirium in the elderly: risk factors and outcomes. Ann. Surg. 249, 173-178. doi: 10.1097/SLA.0B013e31818e4776

Root, J. C., Pryor, K. O., Downey, R., Alici, Y., Davis, M. L., Holodny, A., et al. (2013). Association of pre-operative brain pathology with post-operative delirium in a cohort of non-small cell lung cancer patients undergoing surgical resection. Psychooncology 22, 2087-2094. doi: 10.1002/pon.3262

Rothenburger, M., Soeparwata, R., Deng, M. C., Berendes, E., Schmid, C., Tjan, T. D. T., et al. (2001). The impact of anti-endotoxin core antibodies on endotoxin and cytokine release and ventilation time after cardiac surgery. $J$. Am. Coll. Cardiol. 38, 124-130. doi: 10.1016/s0735-1097(01)01323-7

Rudolph, J. L., Marcantonio, E. R., Culley, D. J., Silverstein, J. H., Rasmussen, L. S., Crosby, G. J., et al. (2008a). Delirium is associated with early postoperative cognitive dysfunction. Anaesthesia 63, 941-947. doi: 10.1111/j.1365-2044.2008. 05523.x

Rudolph, J. L., Ramlawi, B., Kuchel, G. A., McElhaney, J. E., Xie, D., Sellke, F. W., et al. (2008b). Chemokines are associated with delirium after cardiac surgery. $J$. Gerontol. A Biol. Sci. Med. Sci. 63, 184-189. doi: 10.1093/gerona/63.2.184

Sag, D., Carling, D., Stout, R. D., and Suttles, J. (2008). Adenosine 5'monophosphate-activated protein kinase promotes macrophage polarization to an anti-inflammatory functional phenotype. J. Immunol. 181, 8633-8641. doi: 10.4049/jimmunol.181.12.8633

Salani, F., Ciaramella, A., Bizzoni, F., Assogna, F., Caltagirone, C., Spalletta, G., et al. (2013). Increased expression of Interleukin-18 receptor in blood cells of subjects with mild cognitive impairment and Alzheimer's disease. Cytokine 61, 360-363. doi: 10.1016/j.cyto.2012.11.001

Salminen, A., Hyttinen, J. M. T., and Kaarniranta, K. (2011). AMP-activated protein kinase inhibits NF- $\mathrm{B}$ signaling and inflammation: impact on healthspan and lifespan. J. Mol. Med. (Berl.) 89, 667-676. doi: 10.1007/s00109011-0748-0

Scherzer, C. R., Eklund, A. C., Morse, L. J., Liao, Z., Locascio, J. J., Fefer, D., et al. (2007). Molecular markers of early Parkinson's disease based on gene expression in blood. Proc. Natl. Acad. Sci. U S A 104, 955-960. doi: 10. 1073/pnas.0610204104

Shalev, H., Serlin, Y., and Friedman, A. (2009). Breaching the blood-brain barrier as a gate to psychiatric disorder. Cardiovasc. Psychiatry Neurol. 2009:278531. doi: 10.1155/2009/278531

Shcheglovitov, A., Shcheglovitova, O., Yazawa, M., Portmann, T., Shu, R., Sebastiano, V., et al. (2013). SHANK3 and IGF1 restore synaptic deficits in neurons from 22q13 deletion syndrome patients. Nature 503, 267-271. doi: 10. $1038 /$ nature 12618 
Shigeta, H., Yasui, A., Nimura, Y., Machida, N., Kageyama, M., Miura, M., et al. (2001). Postoperative delirium and melatonin levels in elderly patients. Am. J. Surg. 182, 449-454. doi: 10.1016/s0002-9610(01)00761-9

Siddiqui, S., Fang, M., Ni, B., Lu, D., Martin, B., and Maudsley, S. (2012). Central role of the EGF receptor in neurometabolic aging. Int. J. Endocrinol. 2012:739428. doi: 10.1155/2012/739428

Soininen, H., Lehtovirta, M., Helisalmi, S., Linnaranta, K., Heinonen, O., and Riekkinen, P. (1995). Increased acetylcholinesterase activity in the CSF of Alzheimer patients carrying apolipoprotein epsilon4 allele. Neuroreport 6, 2518-2520. doi: 10.1097/00001756-199512150-00017

Sørensen, K. D., and Ørntoft, T. F. (2010). Discovery of prostate cancer biomarkers by microarray gene expression profiling. Expert Rev. Mol. Diagn. 10, 49-64. doi: 10.1586/erm.09.74

Stefano, G. B., Bilfinger, T. V., and Fricchione, G. L. (1994). The immuneneuro-link and the macrophage: postcardiotomy delirium, HIV-associated dementia and psychiatry. Prog. Neurobiol. 42, 475-488. doi: 10.1016/03010082(94)90048-5

Steinmetz, J., Christensen, K. B., Lund, T., Lohse, N., Rasmussen, L. S., and ISPOCD Group (2009). Long-term consequences of postoperative cognitive dysfunction. Anesthesiology 110, 548-555. doi: 10.1097/ALN. 0b013e318195b569

Stoicea, N., McVicker, S., Quinones, A., Agbenyefia, P., and Bergese, S. D. (2014). Delirium-biomarkers and genetic variance. Front. Pharmacol. 5:75. doi: 10. 3389/fphar.2014.00075

Sunwoo, M. K., Hong, J. Y., Choi, J., Park, H. J., Kim, S. H., and Lee, P. H. (2013). $\beta$-Synuclein pathology is related to postoperative delirium in patients undergoing gastrectomy. Neurology 80, 810-813. doi: 10.1212/wnl.0b013e3182 840782

Sutinen, E. M., Pirttilä, T., Anderson, G., Salminen, A., and Ojala, J. O. (2012). Proinflammatory interleukin-18 increases Alzheimer's disease-associated amyloid$\beta$ production in human neuron-like cells. J. Neuroinflammation 9:199. doi: 10. 1186/1742-2094-9-199

Takeoka, T., Shinohara, Y., Furumi, K., and Mori, K. (1983). Impairment of bloodcerebrospinal fluid barrier in multiple sclerosis. J. Neurochem. 41, 1102-1108. doi: 10.1111/j.1471-4159.1983.tb09058.x

Tanzi, R. E., Gusella, J. F., Watkins, P. C., Bruns, G. A., St George-Hyslop, P., Van Keuren, M. L., et al. (1987). Amyloid beta protein gene: cDNA, mRNA distribution and genetic linkage near the Alzheimer locus. Science 235, 880-884. doi: 10.1126/science. 2949367

Teixeira, A. L., Barbosa, I. G., Diniz, B. S., and Kummer, A. (2010). Circulating levels of brain-derived neurotrophic factor: correlation with mood, cognition and motor function. Biomark. Med. 4, 871-887. doi: 10.2217/bmm. 10.111

Terrando, N., Eriksson, L. I., Kyu Ryu, J., Yang, T., Monaco, C., Feldmann, M., et al. (2011). Resolving postoperative neuroinflammation and cognitive decline. Ann. Neurol. 70, 986-995. doi: 10.1002/ana.22664

Terrando, N., Monaco, C., Ma, D., Foxwell, B. M. J., Feldmann, M., and Maze, M. (2010). Tumor necrosis factor-alpha triggers a cytokine cascade yielding postoperative cognitive decline. Proc. Natl. Acad. Sci. U S A 107, 20518-20522. doi: 10.1073/pnas.1014557107

Thomassen, E., Renshaw, B. R., and Sims, J. E. (1999). Identification and characterization of SIGIRR, a molecule representing a novel subtype of the IL1R superfamily. Cytokine 11, 389-399. doi: 10.1006/cyto.1998.0452

Tian, A., Ma, H., Cao, X., Zhang, R., Wang, X., and Wu, B. (2015). Vitamin $\mathrm{D}$ improves cognitive function and modulates Th17/T reg cell balance after hepatectomy in mice. Inflammation 38, 500-509. doi: 10.1007/s10753-0149956-4

Tilvis, R. S., Kähönen-Väre, M. H., Jolkkonen, J., Valvanne, J., Pitkala, K. H., and Strandberg, T. E. (2004). Predictors of cognitive decline and mortality of aged people over a 10-year period. J. Gerontol. A Biol. Sci. Med. Sci. 59, 268-274. doi: $10.1093 /$ gerona/59.3.m268

Trzepacz, P. T. (2000). Is there a final common neural pathway in delirium? Focus on acetylcholine and dopamine. Semin. Clin. Neuropsychiatry 5, 132-148. doi: 10.153/SCNP00500132

Tsai, T. L., Sands, L. P., and Leung, J. M. (2010). An update on postoperative cognitive dysfunction. Adv. Anesth. 28, 269-284. doi: 10.1016/j.aan.2010.09.003

Tune, L. E., Damlouji, N. F., Holland, A., Gardner, T. J., Folstein, M. F., and Coyle, J. T. (1981). Association of postoperative delirium with raised serum levels of anticholinergic drugs. Lancet 2, 651-653. doi: 10.1016/S0140-6736(81) 90994-6

van den Boogaard, M., Kox, M., Quinn, K. L., van Achterberg, T., van der Hoeven, J. G., Schoonhoven, L., et al. (2011). Biomarkers associated with delirium in critically ill patients and their relation with long-term subjective cognitive dysfunction; indications for different pathways governing delirium in inflamed and noninflamed patients. Crit. Care 15:R297. doi: 10.1186/cc10598

van der Mast, R. C., van den Broek, W. W., Fekkes, D., Pepplinkhuizen, L., and Habbema, J. D. (2000). Is delirium after cardiac surgery related to plasma amino acids and physical condition? J. Neuropsychiatry Clin. Neurosci. 12, 57-63. doi: 10.1176/jnp.12.1.57

van Gool, W. A., van de Beek, D., and Eikelenboom, P. (2010). Systemic infection and delirium: when cytokines and acetylcholine collide. Lancet 375, 773-775. doi: 10.1016/s0140-6736(09)61158-2

van Munster, B. C., Aronica, E., Zwinderman, A. H., Eikelenboom, P., Cunningham, C., and de Rooij, S. E. J. (2011a). Neuroinflammation in delirium: a postmortem case-control study. Rejuvenation Res. 14, 615-622. doi: 10. 1089/rej.2011.1185

van Munster, B. C., Bisschop, P. H., Zwinderman, A. H., Korevaar, J. C., Endert, E., Wiersinga, W. J., et al. (2010a). Cortisol, interleukins and S100B in delirium in the elderly. Brain Cogn. 74, 18-23. doi: 10.1016/j.bandc.2010.05.010

van Munster, B. C., de Rooij, S. E. J. A., Yazdanpanah, M., Tienari, P. J., Pitkälä, K. H., Osse, R. J., et al. (2010b). The association of the dopamine transporter gene and the dopamine receptor 2 gene with delirium, a meta-analysis. Am. J. Med. Genet. B Neuropsychiatr. Genet. 153B, 648-655. doi: 10.1002/ajmg.b. 31034

van Munster, B. C., Korevaar, J. C., Korse, C. M., Bonfrer, J. M., Zwinderman, A. H., and de Rooij, S. E. (2010c). Serum S100B in elderly patients with and without delirium. Int. J. Geriatr. Psychiatry 25, 234-239. doi: 10.1002/ gps. 2326

van Munster, B. C., Korevaar, J. C., Zwinderman, A. H., Leeflang, M. M., and de Rooij, S. E. J. A. (2009a). The association between delirium and the apolipoprotein E epsilon 4 allele: new study results and a meta-analysis. Am. J. Geriatr. Psychiatry 17, 856-862. doi: 10.1097/jgp.0b013e3181ab8c84

van Munster, B. C., Korevaar, J. C., Zwinderman, A. H., Levi, M., Wiersinga, W. J., and De Rooij, S. E. (2008). Time-course of cytokines during delirium in elderly patients with hip fractures. J. Am. Geriatr. Soc. 56, 1704-1709. doi: 10.1111/j. 1532-5415.2008.01851.x

van Munster, B. C., Korse, C. M., de Rooij, S. E., Bonfrer, J. M., Zwinderman, A. H., and Korevaar, J. C. (2009b). Markers of cerebral damage during delirium in elderly patients with hip fracture. BMC Neurol. 9:21. doi: 10.1186/1471-23779-21

van Munster, B. C., Thomas, C., Kreisel, S. H., Brouwer, J. P., Nanninga, S., Kopitz, J., et al. (2012). Longitudinal assessment of serum anticholinergic activity in delirium of the elderly. J. Psychiatr. Res. 46, 1339-1345. doi: 10. 1016/j.jpsychires.2012.06.015

van Munster, B. C., Yazdanpanah, M., Tanck, M. W. T., de Rooij, S. E. J. A., Van De Giessen, E., Sijbrands, E. J. G., et al. (2010d). Genetic polymorphisms in the DRD2, DRD3 and SLC6A3 gene in elderly patients with delirium. Am. J. Med. Genet. Part B Neuropsychiatr. Genet. 153, 38-45. doi: 10.1002/ajmg.b. 30943

van Munster, B. C., Zwinderman, A. H., and de Rooij, S. E. (2011b). Genetic variations in the interleukin- 6 and interleukin- 8 genes and the interleukin- 6 receptor gene in delirium. Rejuvenation Res. 14, 425-428. doi: 10.1089/rej.2011. 1155

Volkow, N. D., Gur, R. C., Wang, G. J., Fowler, J. S., Moberg, P. J., Ding, Y. S., et al. (1998). Association between decline in brain dopamine activity with age and cognitive and motor impairment in healthy individuals. Am. J. Psychiatry 155, 344-349. doi: 10.1176/ajp.155.3.344

Volpicelli, L. A., and Levey, A. I. (2004). Muscarinic acetylcholine receptor subtypes in cerebral cortex and hippocampus. Prog. Brain Res. 145, 59-66. doi: 10.1016/s0079-6123(03)45003-6

Vom Berg, J., Prokop, S., Miller, K. R., Obst, J., Kälin, R. E., Lopategui-Cabezas, I., et al. (2012). Inhibition of IL-12/IL-23 signaling reduces Alzheimer's diseaselike pathology and cognitive decline. Nat. Med. 18, 1812-1819. doi: 10 1038/nm.2965

Wagner, M., Schulze-Rauschenbach, S., Petrovsky, N., Brinkmeyer, J., von der Goltz, C., Gründer, G., et al. (2013). Neurocognitive impairments in 
non-deprived smokers-Results from a population-based multi-center study on smoking-related behavior. Addict. Biol. 18, 752-761. doi: 10.1111/j.1369-1600. 2011.00429.x

Wald, D., Qin, J., Zhao, Z., Qian, Y., Naramura, M., Tian, L., et al. (2003). SIGIRR, a negative regulator of Toll-like receptor-interleukin 1 receptor signaling. Nat. Immunol. 4, 920-927. doi: 10.1038/ni968

Wan, C., La, Y., Zhu, H., Yang, Y., Jiang, L., Chen, Y., et al. (2007). Abnormal changes of plasma acute phase proteins in schizophrenia and the relation between schizophrenia and haptoglobin (Hp) gene. Amino Acids 32, 101-108. doi: 10.1007/s00726-005-0292-8

Wan, Y., Xu, J., Meng, F., Bao, Y., Ge, Y., Lobo, N., et al. (2010). Cognitive decline following major surgery is associated with gliosis, $\beta$-amyloid accumulation and $\tau$ phosphorylation in old mice. Crit. Care Med. 38, 2190-2198. doi: 10. 1097/CCM.0b013e3181f17bcb

Wang, Y., He, H., Li, D., Zhu, W., Duan, K., Le, Y., et al. (2013). The role of the TLR4 signaling pathway in cognitive deficits following surgery in aged rats. Mol. Med. Rep. 7, 1137-1142. doi: 10.3892/mmr.2013.1322

Wang, X., Yu, J., Sreekumar, A., Varambally, S., Shen, R., Giacherio, D., et al. (2005). Autoantibody signatures in prostate cancer. N. Engl. J. Med. 353, 1224-1235. doi: 10.1056/NEJMoa051931

Wenk, G. L. (2003). Neuropathologic changes in Alzheimer's disease. J. Clin. Psychiatry 64, 7-10.

Wessel, J., McDonald, S. M., Hinds, D. A., Stokowski, R. P., Javitz, H. S., Kennemer, M., et al. (2010). Resequencing of nicotinic acetylcholine receptor genes and association of common and rare variants with the Fagerström test for nicotine dependence. Neuropsychopharmacology 35, 2392-2402. doi: 10.1038/npp. 2010.120

Willard, B., Hauss-Wegrzyniak, B., and Wenk, G. L. (1999). Pathological and biochemical consequences of acute and chronic neuroinflammation within the basal forebrain cholinergic system of rats. Neuroscience 88, 193-200. doi: 10 . 1016/s0306-4522(98)00216-4

Wilson, K., Broadhurst, C., Diver, M., Jackson, M., and Mottram, P. (2005). Plasma insulin growth factor-1 and incident delirium in older people. Int. J. Geriatr. Psychiatry 20, 154-159. doi: 10.1002/gps.1265

Winterer, G. (2010). Why do patients with schizophrenia smoke? Curr. Opin. Psychiatry 23, 112-119. doi: 10.1097/yco.0b013e3283366643

Winterer, G., Mittelstrass, K., Giegling, I., Lamina, C., Fehr, C., Brenner, H., et al. (2010). Risk gene variants for nicotine dependence in the CHRNA5CHRNA3-CHRNB4 cluster are associated with cognitive performance. Am. J. Med. Genet. B Neuropsychiatr. Genet. 153, 1448-1458. doi: 10.1002/ajmg.b. 31126
Winterer, G., Musso, F., Konrad, A., Vucurevic, G., Stoeter, P., Sander, T., et al. (2007). Association of attentional network function with exon 5 variations of the CHRNA4 gene. Hum. Mol. Genet. 16, 2165-2174. doi: 10. 1093/hmg/ddm 168

Wu, Y., Wang, J., Wu, A., and Yue, Y. (2014). Do fluctuations in endogenous melatonin levels predict the occurrence of postoperative cognitive dysfunction (POCD)? Int. J. Neurosci. 124, 787-791. doi: 10.3109/00207454.2014.882919

Xie, P., Kranzler, H. R., Krauthammer, M., Cosgrove, K. P., Oslin, D., Anton, R. F., et al. (2011). Rare nonsynonymous variants in alpha-4 nicotinic acetylcholine receptor gene protect against nicotine dependence. Biol. Psychiatry 70, 528-536. doi: 10.1016/j.biopsych.2011.04.017

Yaffe, K., Kanaya, A., Lindquist, K., Simonsick, E. M., Harris, T., Shorr, R. I., et al. (2004). The metabolic syndrome, inflammation and risk of cognitive decline. JAMA 292, 2237-2242. doi: 10.1001/jama.292.18.2237

Yang, Y.-R., Liu, S.-L., Qin, Z.-Y., Liu, F.-J., Qin, Y.-J., Bai, S.-M., et al. (2008). Comparative proteomics analysis of cerebrospinal fluid of patients with Guillain-Barré syndrome. Cell. Mol. Neurobiol. 28, 737-744. doi: 10. 1007/s10571-007-9257-7

Yoshitaka, S., Egi, M., Morimatsu, H., Kanazawa, T., Toda, Y., and Morita, K. (2013). Perioperative plasma melatonin concentration in postoperative critically ill patients: its association with delirium. J. Crit. Care 28, 236-242. doi: 10.1016/j.jcrc.2012.11.004

Zhang, Y.-H., Guo, X.-H., Zhang, Q.-M., Yan, G.-T., and Wang, T.-L. (2014a). Serum CRP and urinary trypsin inhibitor implicate postoperative cognitive dysfunction especially in elderly patients. Int. J. Neurosci. doi: 10 3109/00207454.2014.949341 [Epub ahead of print].

Zhang, Z., Pan, L., Deng, H., Ni, H., and Xu, X. (2014b). Prediction of delirium in critically ill patients with elevated C-reactive protein. J. Crit. Care 29, 88-92. doi: 10.1016/j.jcrc.2013.09.002

Conflict of Interest Statement: The authors declare that the research was conducted in the absence of any commercial or financial relationships that could be construed as a potential conflict of interest.

Copyright (c) 2015 Androsova, Krause, Winterer and Schneider. This is an openaccess article distributed under the terms of the Creative Commons Attribution License (CC BY). The use, distribution and reproduction in other forums is permitted, provided the original author(s) or licensor are credited and that the original publication in this journal is cited, in accordance with accepted academic practice. No use, distribution or reproduction is permitted which does not comply with these terms. 